\title{
Oxi-redox Selective Breast Cancer Treatment: An In-vitro Study of Theranostic In-based Oxide Nanoparticles for Controlled Generation or Prevention of Oxidative Stress
}

Nai-Sheng HSU ${ }^{a, b}$, Moeava Tehei ${ }^{b, d}$, Md Shahriar Hossain ${ }^{e}$, Anatoly Rosenfeld ${ }^{b, d}$, Muhammad J. A. Shiddiky, Ronald Slyuter ${ }^{b, c}$, Shi Xue Dou ${ }^{a}$, Yusuke Yamauchi ${ }^{* * g}$ and Konstantin Konstantinov $* a, b$

${ }^{a}$ Institute for Superconducting and Electronic Materials, Australian Institute for Innovative Materials, University of Wollongong, 2500 North Wollongong, NSW, Australia.

${ }^{b}$ Illawarra Health and Medical Research Institute, University of Wollongong, 2500 Wollongong, NSW, Australia.

${ }^{c}$ School of Chemistry and Medical Biology, Faculty of Science, Medicine and Health, University of Wollongong, 2500 Wollongong, NSW, Australia.

${ }^{d}$ Centre for Medical and Radiation Physics, Faculty of Engineering and Information Science, University of Wollongong, 2500 Wollongong, NSW, Australia.

e Australian Institute for Bioengineering and Nanotechnology, School of Mechanical and Mining Engineering, Faculty of Engineering, Architecture and Information Technology, The University of Queensland, 4072 Brisbane, QLD, Australia

${ }^{f}$ School of Environment and Science (ESC) \& Queensland Micro- and Nanotechnology Centre (QMNC), Griffith University, Nathan campus, Nathan, QLD 4111, Australia $g$ Australian Institute for Bioengineering and Nanotechnology, School of Chemical Engineering, The University of Queensland, 4702 Brisbane, QLD, Australia

Corresponding authors: konstan@uow.edu.au; y.yamauchi@uq.edu.au

\section{Keywords}

Engineered ITO NPs, multifunctional theranostic system, controlled ROS scavenging/generation, surface defects, breast cancer treatment. 


\section{GRAPHIC ABSTRACT}

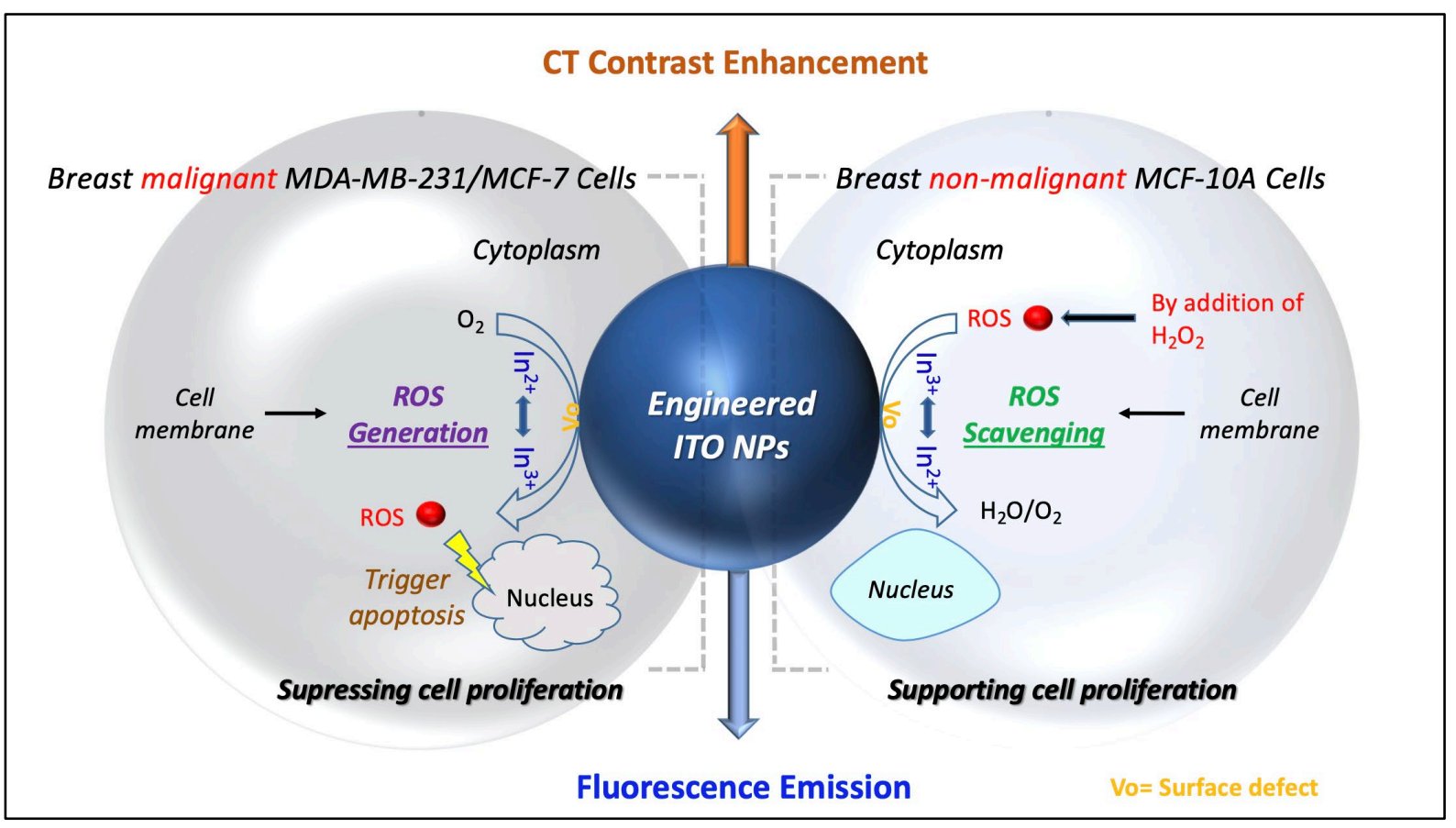

In this article we demonstrate that specifically engineered oxide nanoparticles have the potential to act as theranostic materials able to generate or prevent oxidative stress through their oxi-redox activity in various types of malignant and non-malignant cells. The oxi-redox activity is related to the type and presence of surface defects, which is modified with appropriate synthesis conditions. In the present work, we used MDA-MB-231 and MCF-7 human breast cancer cells, and non-malignant MCF-10A human breast cells to demonstrate how controlled oxidative stress mediated by specifically nano-engineered indium tin oxide (ITO) nanoparticles (NPs) can selectively induce cell death in the cancer cells while reducing the oxidative stress in the normal cells and supporting their proliferation. The ITO NPs are also promising nano-theranostic materials for cancer therapy and contrast agents due to their multimodal imaging capabilities. We demonstrate that the synthesized ITO NPs can selectively increase the generation of reactive oxygen species (ROS) in both breast tumor cell lines, resulting in activation of apoptosis, and can also greatly suppress the cellular proliferation in both types of tumor cells. In contrast, the ITO NPs exhibit ROS scavenging-like behaviour, significantly decreasing the ROS levels in MCF-10A cells exposed to the additional ROS, hydrogen peroxide $\left(\mathrm{H}_{2} \mathrm{O}_{2}\right)$, so that they protect the proliferation of non-malignant MCF-10A cells from ROS damage. In addition, fluorescent microscopy images revealed that the ITO NPs emit strong fluorescence that could be used to reveal their location. Moreover, computed tomography (CT) imaging demonstrated that the ITO NPs exhibited a comparable 
capability towards anatomical contrast enhancement. These results suggest that the synthesized ITO NPs have the potential to be a novel selective therapeutic agent with a multimodal imaging property for anticancer treatment.

\section{INTRODUCTION}

Oxidative stress is a globally damaging mechanism in all biological systems, and is caused by an imbalance between the production of ROS and the ability of biological systems to readily detoxify the reactive intermediates or easily repair the resulting damage. (Break)

ROS is a term collectively describing reactive oxygen derived free radicals such as hydroxyl $(\cdot \mathrm{OH})$, superoxide anion $\left(\mathrm{O}_{2}^{-}\right)$, nitric oxide $(\mathrm{NO} \cdot)$, and peroxyl $\left(\mathrm{RO}_{2} \cdot\right)$, as well as non-radical reactive oxygen derivatives, including hydrogen peroxide $\left(\mathrm{H}_{2} \mathrm{O}_{2}\right)$, singlet oxygen $\left({ }^{-} \mathrm{O}_{2}\right)$, ozone $\left(\mathrm{O}_{3}\right)$, and lipid peroxide $(\mathrm{LOOH}){ }^{1}$ (Break)

Excessive ROS that cannot be eliminated by the biological antioxidant system will lead to oxidative stress damage to all cell components, including protein oxidation, lipid peroxidation, and deoxyribonucleic acid (DNA) damage..$^{2-4}$ It has been revealed that oxidative stress is involved in many human diseases, including Alzheimer's disease, Parkinson's disease, strokes, diabetes, inflammation disorders, cancer, and so on. ${ }^{5-7}$ Therefore, a controlled ROS prevention may reduce the incidence of the ROS-involved diseases. ${ }^{8-10}$ Nevertheless, ROS is a double-edge sword; cellular production of ROS plays a very significant positive role in physiological responses in a number of cases including cell redox signaling, cell homeostasis, and cellular

apoptosis (programmed cell death), ${ }^{2,11-13}$ where induction of cellular apoptosis in cancer cells has become a conventional strategy in nanomedicine for cancer therapy.

Recent nanomedicine including several types of nanosized metal oxide materials, have been reported to induce ROS which then activate apoptosis in cancer cells, consequently promoting cancer cell death. ${ }^{14-20}$ It has been reported that iron oxide nanoparticles (NPs) can transform near-infrared radiation (NIR) or an oscillating magnetic field (MF) into toxic stimuli to prompt ROS generation, and to further induce apoptosis of MCF-7 and Caco-2 human tumor cells. ${ }^{14}$ Studies also show that cuprous oxide NPs could selectively activate the apoptosis of tumor cells through ROS generation. ${ }^{15,16}$ Zinc oxide NPs have also been demonstrated a selective tumor-killing capability that acts through ROS induced apoptosis of cancer cells. ${ }^{17,18}$ Cobalt oxide NPs coated with phosphonomethyl iminodiacetic acid (PMIDA-CoO) have been shown the ability to induce ROS generation and promote apoptosis in leukemic cells. ${ }^{19}$ A study also reports that nickel oxide NPs have been shown their anticancer ability through ROS mediated cell death in malignant MCF-7 cells. ${ }^{20}$ Although some 
authors of these studies have pointed out that their materials possess "selectivity" between tumor and nonmalignant cells, they often refer to the "selectivity" as meaning no harm or only moderate toxicity to the reference non-malignant cells rather than any claims for the ability of the studied materials to protect the nonmalignant cells from oxidative stress through ROS scavenging. On the other hand, although some research results demonstrate that some nanosized metal oxide materials can act as ROS scavengers to prevent oxidative stress induced cell death, ${ }^{21-25}$ only few studies, however, have explored the potential of metal oxide NPs to exhibit both useful oxy/redox properties and an ability to act as ROS generators in tumor cells, but perform as ROS scavengers in normal cells. In fact, until recent, only cerium oxide NPs have been found to show ROS generation/scavenging behaviour in cancer and normal cells, respectively, through their redox capability and oxygen defects. $^{26-32}$ To the best of our knowledge, the cerium oxide NPs, however, do not show high cytotoxicity when exposed to cancer cells alone, and they may need to be combined with radiation or other anticancer drugs to maximize their therapeutic efficacy. ${ }^{26,29,30,32}$ In addition, nanosized metal oxide NPs can be designed as a perfect theranostic system where one material possesses all the required imaging, therapeutic, and selective properties, rather than using a complex assembly of composite theranostic particles containing four different components, such as a drug carrier, drug agent, imaging agent, and target vector. ${ }^{33-35}$ Although many metal oxide NPs demonstrate their multimodal imaging properties plus an anticancer ability, which are highly beneficial and favourable for biomedical applications, these theranostic nanomaterials often require complicated processes for synthesis. ${ }^{36-38}$ Therefore, the motivation behind this work is to investigate a novel, simple synthesized nanotheranostic system which not only possesses distinguished selectivity given through the mediation of controlled generation or prevention of oxidative stress, but also exhibits extremely high therapeutic efficacy on malignant cells in cancer treatment.

In the present work, we have studied a novel candidate for such a theranostic metal oxide nanomaterial based on nano-engineered indium tin oxide (ITO). Particularly, we designed to induce more oxygen defects on the surface of the prepared ITO NPs, and to induce changes to the valence states of indium in the as-prepared NPs, which could modify some of the physicochemical properties of the designed ITO NPs. ITO NPs are known as an n-type semiconductor and have been extensively applied in a variety of applications. ${ }^{39}$ ITO NPs are intrinsic fluorescent ${ }^{40}$ and could also be used for bioimaging due to the properties of their band gap and the quantum size effect. ${ }^{41-42}$ In addition, due to the high atomic number of In and Sn elements, ITO could be used for anatomical contrast enhancement. These features of ITO NPs can be useful for their novel application as a theranostic agent for cancer therapy and other biomedical applications. 


\section{RESULTS AND DISSCUSSION}

\subsection{Characterization of the synthesized ITO NPS}

The X-ray powder diffraction pattern of the obtained ITO NPs is shown in Figure 1A. The corresponding peaks in Figure 1A demonstrate that the synthesized nanomaterials are a single phase of $\operatorname{In}_{2} \mathrm{O}_{3}$ powders with body-centred cubic crystalline structure, in which no significant peaks corresponding to $\mathrm{SnO}, \mathrm{SnO}_{2}$ or other impurities were detected, and the ITO lattice parameter remained unchanged, according to the Joint Committee on Powder Diffraction Standards file (JCPDS \# 06-0416). The results suggest that the Sn atoms were well incorporated into the $\mathrm{In}_{2} \mathrm{O}_{3}$ crystal lattice. Figure 1B represents the results of the energy dispersive X-ray spectroscopy (EDS) analysis, showing that no other elemental impurity was present in the prepared ITO crystal structure. The characteristics of the final powders with an expected weight ratio of approximately $9: 1$ of $\mathrm{In}_{2} \mathrm{O}_{3}$ to $\mathrm{SnO}_{2}$ are displayed in Supplementary Table S1. The average crystallite size $(d)$ of the prepared ITO NPs can be calculated by the Scherrer equation, based on the XRD pattern. The calculated average crystallite size of the synthesized ITO NPs was found to be $10.78 \pm 1.42 \mathrm{~nm}$. Figure 1(C-D) shows transmission electron microscope (TEM) and high-resolution TEM (HRTEM) image with the fast Fourier transform (FFT) pattern of the ITO NPs. As can be seen from Figure 1C, the synthesized ITO NPs mainly formed aggregates greater than $50 \mathrm{~nm}$ in size. The HRTEM image displayed in Figure 1D reveals the ITO nanostructure with lattice spacing of $0.29,0.25$, and $0.18 \mathrm{~nm}$, which are in accordance with the $d$-spacing of the (222), (004), and (440) planes, respectively. The results are in agreement with our XRD spectrum (Figure. 1A). The inset of FFT pattern in Figure 1D presents the major lattice planes, which also confirms the crystallinity of the ITO NPs. 
A

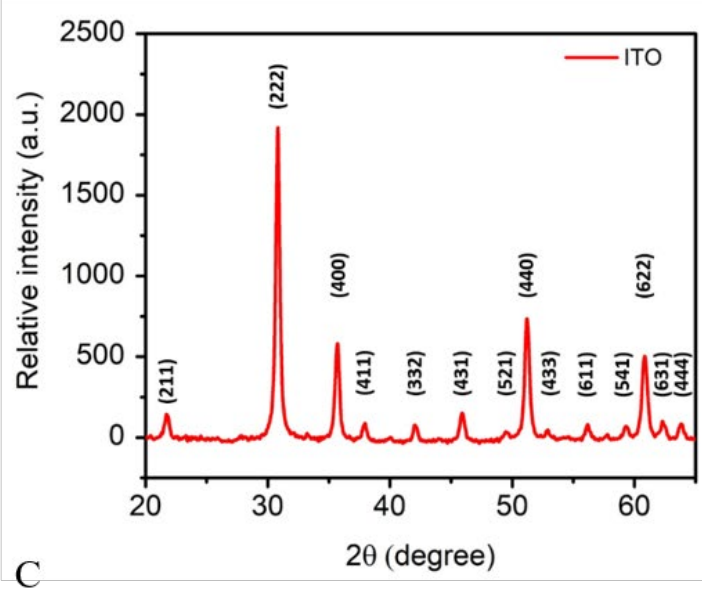

$\mathrm{B}$

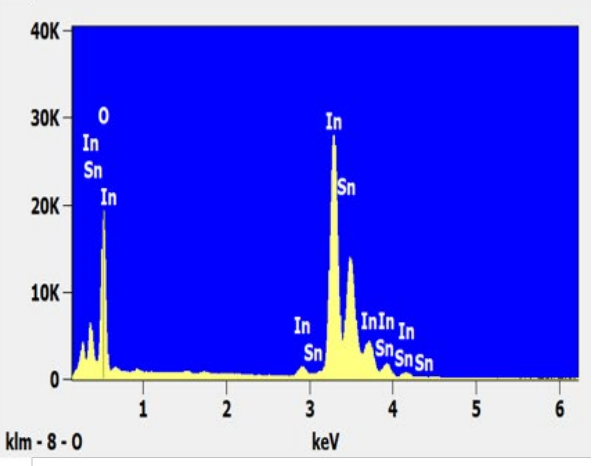

$\mathrm{D}$

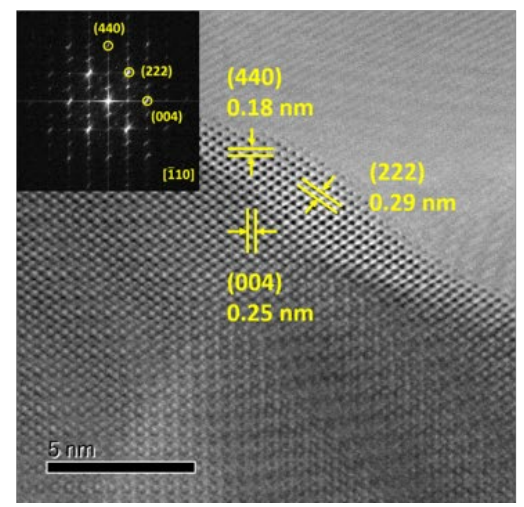

Figure 1. X-ray diffraction pattern (A), EDS spectrum (B), TEM image (C), and HR-TEM image with an inset of corresponding FFT pattern (D) of the synthesized ITO NPs.

Dynamic light scattering was performed to evaluate the hydrodynamic size of the prepared ITO NPs dispersed in PBS, and the intensity-based size distributions of the particles are presented in Table 1. The results show that the hydrodynamic diameters of the present ITO NPs in PBS were less than $8 \%$ on the nanoscale, and the main hydrodynamic size of the ITO dispersion was $174.1 \pm 14.02 \mathrm{~nm}$. The larger size of the ITO NPs in aqueous suspension differed from the size measured by XRD and TEM, which could be attributed to the high tendency towards particle agglomeration in the aqueous state. This finding is supported by others. ${ }^{15,43}$ The original dynamic light scattering data are presented in Figure 2.

Table 1. Hydrodynamic diameters and intensities (Int) of ITO NPs suspended in PBS after 2 hours of sonication, characterized via dynamic light scattering. The concentration of the nanomaterials is $50 \mu \mathrm{g} / \mathrm{mL}$.

\begin{tabular}{ccccc}
\hline Material & Peak 1 $(\mathrm{nm})$ & Int 1 $(\%)$ & Peak 2 $(\mathrm{nm})$ & Int 2 (\%) \\
\hline ITO & $3.102 \pm 0.1162$ & 7.8 & $174.1 \pm 14.02$ & 92.2 \\
\hline
\end{tabular}




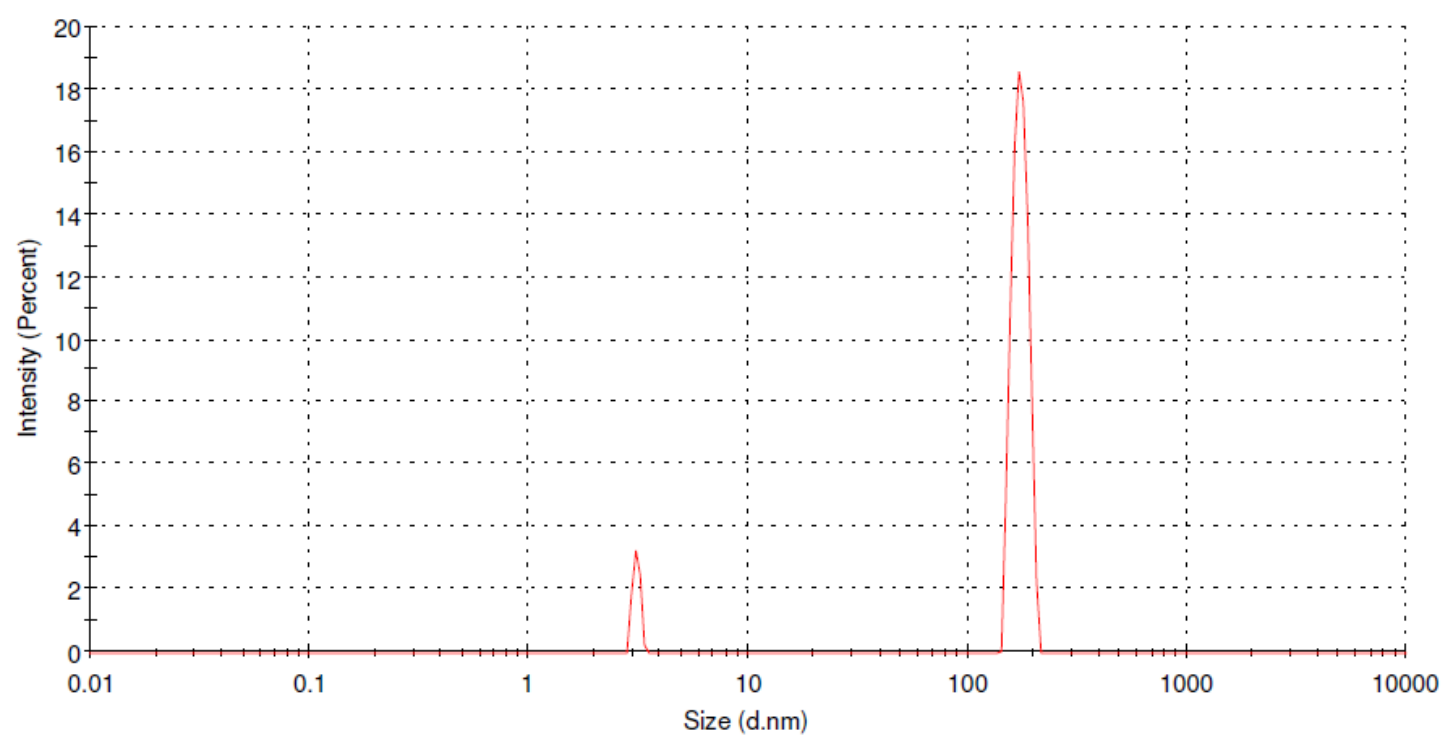

Figure 2. Hydrodynamic diameter of ITO NPs suspended in PBS, determined via dynamic light scattering. The concentration of the suspension of ITO NPs is $50 \mu \mathrm{g} / \mathrm{mL}$.

XPS was performed to examine the chemical composition and the surface property of the prepared ITO NPs. Figure 3 displays the corresponding XPS spectra of the In 3d, Sn 3d, and O 1s core levels of the asprepared ITO NPs. In Figure 3A, the peaks located at $444 \pm 0.2 \mathrm{eV}$ and $452.3 \pm 0.2 \mathrm{eV}$ were assigned to the binding energies of In $3 \mathrm{~d}_{3 / 2}$, and In $3 \mathrm{~d}_{5 / 2}$, respectively, and these peaks were ascribed to In ions in the In-O bonds, whereas no asymmetric peak corresponding to metallic In was found, suggesting that all In ions were in the oxide forms.$^{44}$ Figure 3B shows two symmetric peaks located at $486 \pm 0.2 \mathrm{eV}$ and $494.6 \pm 0.2 \mathrm{eV}$ are corresponding to the binding energies of Sn $3 \mathrm{~d}_{3 / 2}$ and $\mathrm{Sn} 3 \mathrm{~d}_{5 / 2}$, respectively for the prepared ITO NPs. These binding energies of the Sn 3d peaks ( $\mathrm{Sn} 3 \mathrm{~d}_{3 / 2}:>486.2 \mathrm{eV}$ ) were very close to those of tin oxide ( $\mathrm{Sn}_{\text {oxide }} 3 \mathrm{~d}_{3 / 2}$ : $486.4 \mathrm{eV}),{ }^{45}$ but far away from that of metallic $\mathrm{Sn}\left(\mathrm{Sn}_{\text {metal }} 3 \mathrm{~d}_{3 / 2}: 484.9 \mathrm{eV}\right),{ }^{44}$ suggesting that all the $\mathrm{Sn}$ ions were in the valence state of $\mathrm{Sn}^{4+}$ and were well integrated into the crystalline structure of the prepared ITO NPs. The results are consistent with our results from XRD analysis. In Figure $3 \mathrm{C}$, the $\mathrm{O} 1 \mathrm{~s}$ peak was deconvoluted by a Gaussian function into three components with variable intensities in approximately the same positions, namely, OI, OII, and OIII, and all the components could be assigned based on the literature on ITO materials. ${ }^{44-48}$ Component $\mathrm{O}_{\mathrm{I}}$ of $\mathrm{O} 1 \mathrm{~s}$ at $529.6 \mathrm{eV} \pm 0.2 \mathrm{eV}$ is due to bulk $\mathrm{O}^{2-}$ ions with neighbouring In atoms that possess a full complement of six nearest neighbour $\mathrm{O}^{2-}$ ions, ${ }^{44,47}$ while $\mathrm{O}_{\text {II }}$ at $531.5 \pm 0.2 \mathrm{eV}$ corresponds to $\mathrm{O}^{2-}$ ions in oxygen deficient sites, where the indium atoms are no longer fully coordinated with oxygen atoms due to the generation of oxygen defects. ${ }^{44,46-47}$ Peak $\mathrm{O}_{\text {III }}$ at $533.1 \pm 0.2 \mathrm{eV}$ is associated with the oxygen of free hydroxyl groups, which is possibly due to water molecules adsorbed onto the surface, a phenomenon 
that seems inevitable and commonly exists in ITO materials. ${ }^{46,48}$ In addition, there are two oxygen chemical states, $\mathrm{O}^{2-}$ and $\mathrm{OH}^{-}$, existing in both the OI and the OII areas of ITO materials, and were very difficult to distinguish by fitting with binding energy. Therefore, we introduced the electroneutrality principle ${ }^{46}$ to understand the possible oxygen chemical states for our ITO NPs. In brief, when Sn exists solely as a substitutional dopant in the $\mathrm{In}_{2} \mathrm{O}_{3}$ matrix, the theoretical ratio of $\left(\mathrm{O}_{\mathrm{I}}+\mathrm{O}_{\mathrm{II}}\right) /(\mathrm{In}+\mathrm{Sn})$ is $1.5(1.55$ for interstitial $\mathrm{Sn}$ ) if all oxygen exists in the form of $\mathrm{O}^{2-}$; or 3.0 to 3.1 when all the oxygen is in the form of $\mathrm{OH}^{-} .49 \mathrm{Table}^{2}$ shows the experimental value of 1.80 , which not only indicates a large prevalence of $\mathrm{O}^{2-}$, but also suggests the possible existence of $\mathrm{OH}^{-}$in the studied ITO NPs. Thus, by integrating the deconvoluted O 1s, In $3 \mathrm{~d}$, and Sn $3 \mathrm{~d}$ peak areas, it can be clearly identified that oxygen deficiencies were introduced on the surfaces of our ITO NPs. Furthermore, the binding energies of $\operatorname{In} 3 \mathrm{~d}_{3 / 2}$ and $\mathrm{Sn} 3 \mathrm{~d}_{3 / 2}$ for our ITO NPs were lower than $444.8\left(\operatorname{In}_{2} \mathrm{O}_{3}\right)$ and $486.4 \mathrm{eV}\left(\mathrm{SnO}_{2}\right)$, respectively, which also confirm the existence of the oxygen deficiencies, because the binding energies of In and Sn are also decreased by oxygen deficiency. ${ }^{50,51}$

Table 2. The atomic ratios of $\mathrm{Sn}, \mathrm{O}_{\mathrm{I}}$, and $\mathrm{O}_{\mathrm{II}}$ components normalised to In for the as-prepared ITO NPs.

\begin{tabular}{cccc}
\hline \multicolumn{1}{c}{ Sample } & $\mathrm{Sn}$ & $\mathrm{O}_{\mathrm{I}} / \mathrm{O}_{\text {II }}$ & $\left(\mathrm{O}_{\mathrm{I}} / \mathrm{O}_{\text {II }}\right) /(\mathrm{In}+\mathrm{Sn})$ \\
\hline ITO-1 (In present study) & 0.22 & $0.83 / 1.37$ & 1.80 \\
ITO-2 & 0.21 & $0.69 / 1.09$ & 1.50 \\
\hline
\end{tabular}

Note: ITO-1 NPs are the material that we studied in this article.

ITO-2 NPs are the material synthesized under the same conditions as ITO-1 but annealed in air. 


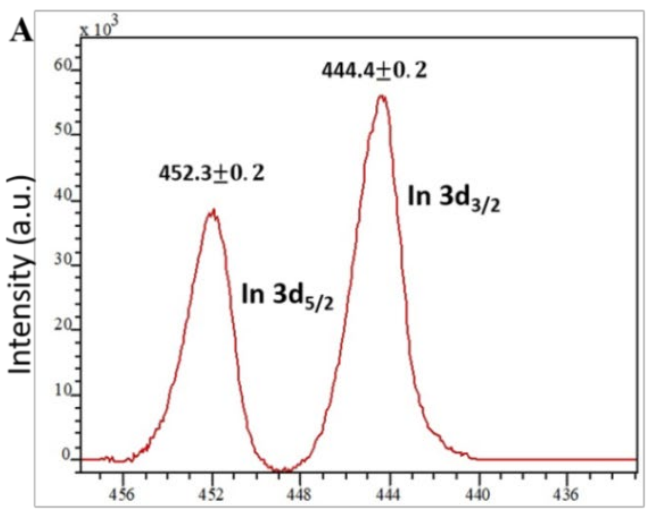

Binding Energy (eV)

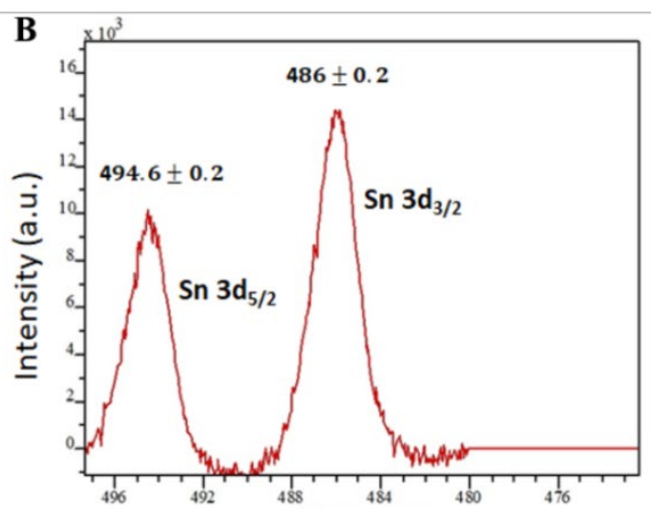

Binding Energy (eV)

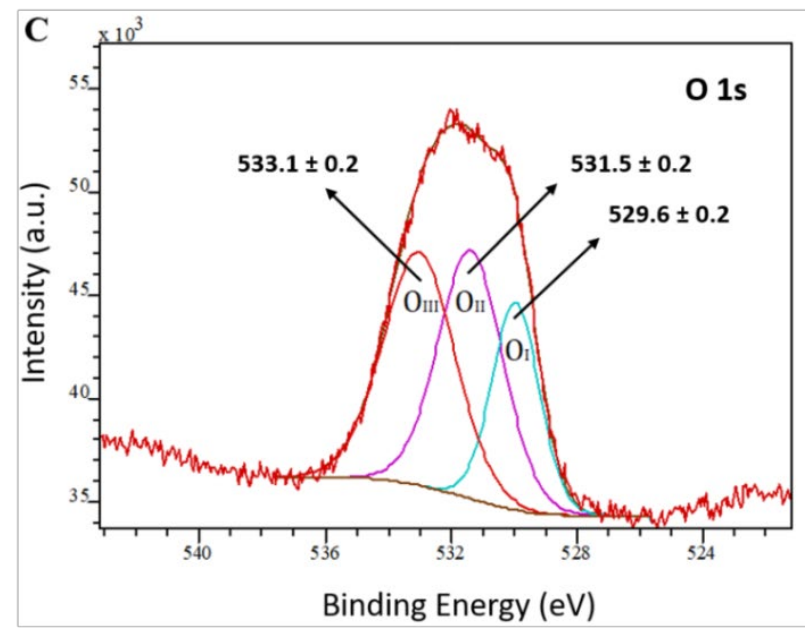

Figure 3. High-resolution XPS spectra of (A) In 3d, (B) Sn 3d, and (C) O 1s of the ITO-1 NPs.

In order to further quantify the oxygen defects (vacancies) for the studied ITO NPs, the relative ratio of the oxygen vacancy to total oxygen was calculated, ${ }^{48}$ and the results are shown in Table 3 . Clearly, the ITO NPs synthesized in a reducing environment created more oxygen vacancies, and those oxygen defects may play a vital role in mediating the reduction of reactive oxygen species.

Table 3. Quantitative results on ITO NPs obtained by XPS calculations.

\begin{tabular}{lccccc}
\hline \multicolumn{1}{c}{ Sample } & O (at \%) & In (at \%) & Sn (at \%) & Sn / In & $\begin{array}{c}\text { Vo / O total } \\
\text { (Oxygen deficiency \%) }\end{array}$ \\
\hline ITO-1 (Present studied) & $66.25 \%$ & $27.58 \%$ & $6.17 \%$ & $22.37 \%$ & $25.03 \%$ \\
ITO-2 & $65.60 \%$ & $28.44 \%$ & $5.96 \%$ & $20.96 \%$ & $20.36 \%$ \\
\hline
\end{tabular}

Note: ITO-1 NPs are the material that we studied in this article.

ITO-2 NPs are the material synthesized under the same conditions as ITO-1 but annealed in air.

ITO-2 NPs induced ROS generation in both types of cancer cells, but not in normal cells, and they did not show any ROSscavenging behaviour in normal cells. Data is shown in Supporting Figure S1. 
The high-resolution XPS spectrum of O 1s of ITO-2 NPs is shown in Supporting Figure S2.

It is also worth understanding the chemical states of In ions in the synthesized ITO NPs, although they are difficult to observe directly from the XPS spectra, the changes in the chemical states of the synthesized ITO NPs could be examined though comparison of the XPS spectra of In $3 \mathrm{~d}_{3 / 2}$ of ITO-1 (present study) and ITO-2 (the ITO NPs synthesized under the same condition with ITO-1, but annealed in air). ${ }^{52,53}$ The discussion on high-resolution XPS spectra of In 3d $\mathrm{d}_{3 / 2}$ of ITO-1 and ITO-2 NPs is given in the Supporting Figure S3.

\subsection{Cellular internalization and fluorescence of ITO NPS}

Flow cytometry measurements of the SSC were used to determine the relative cellular uptake of $\mathrm{NPs}^{54}$, 55 into MDA-MB-231, MCF-7, and MCF-10A cells. The detailed discussion on relative cellular internalization of ITO NPs measured by flow cytometry is given in the Supporting Figure S4.

Cellular internalization can also be revealed through detection of the intrinsic fluorescence emitted from ITO NPs by using fluorescence microscopy. ${ }^{55}$ The images were representative of MDA-MB-231, MCF-7, and MCF-10A cells and have been chosen to visually display the intrinsic fluorescence of the ITO NPs, which could be further used to navigate the location of the ITO NPs, hence showing their cellular uptake. The fluorescence (left), the bright field (middle), and the overlay of the fluorescence and bright field (right) images with the different top, middle, and bottom z-positions of the MDA-MB-231, MCF-7, and MCF-10A cells treated with ITO for $24 \mathrm{~h}$ are shown in Figure 4A, 4B, and 4C, respectively. In Figures 4, the top, middle, and bottom z-position images are corresponded respectively to the $1^{\text {st }}, 21^{\text {st }}$, and $41^{\text {st }}$ (Figure $4 \mathrm{~A}$ ), the $1^{\text {st }}, 26^{\text {th }}$, and $51^{\text {st }}$ (Figure 4B), and the $1^{\text {st }}, 12^{\text {th }}$, and $23^{\text {rd }}$ (Figure 4C) sections. These z-position images were the sliced images taken from the top to the bottom of the cells. A total of 41 slices were imaged with $0.50 \mu \mathrm{m}$ intervals, as shown in Figure 4A, 51 slices were taken with $0.82 \mu \mathrm{m}$ intervals, as shown in Figure 4B, and 23 slices were captured with $1.96 \mu \mathrm{m}$ intervals, as shown in Figure 4C. By comparing ITO NP-treated cells ( Figure 4) with untreated

cells (Supplementary Figure S5), Figure 4 clearly demonstrates that ITO NPs emitted a very strong fluorescence, even upon longer exposure time, suggesting these NPs could be used for theranostic purposes. The fluorescent images of those cells without ITO NPs exposure are presented in Supporting Figure S5, which does not show any detectable fluorescence.

By analysing the fluorescent strength through the z-positions of all ITO NP-treated cell-imaging slices using Image J software, the internalization of the ITO particles could be determined. As shown in Figure 4 and in Supporting Figures S6-S8 where the cellular uptake of ITO NPs in cytoplasm was marked by the red circle. To note, due to the size and the surface charge of the nature properties of metal oxide NPs, these nanoparticles 
tend to aggregate and may stick around cell surfaces. In addition, through our DSL results, most ITO NPs were with an agglomerated hydrodynamic size bigger than $150 \mathrm{~nm}$, this could hinder their intracellular transportation. Nevertheless, in Figure 4, it seems many other parts of cells also showed strong fluorescence, but were not indicated. This was because when ITO NPs were aggregated they emitted very strong fluorescence, and once these agglomerated ITO NPs were sticking around the surface of the cells, cellular internalization could not be easily determined. Therefore, the location of the ITO NPs within a cell was not able to indicate.

The Supporting Figures S6-S8 respectively demonstrate more detailed middle consecutive slices for MDA-MB-231, MCF-7, and MCF-10A with ITO NPs.

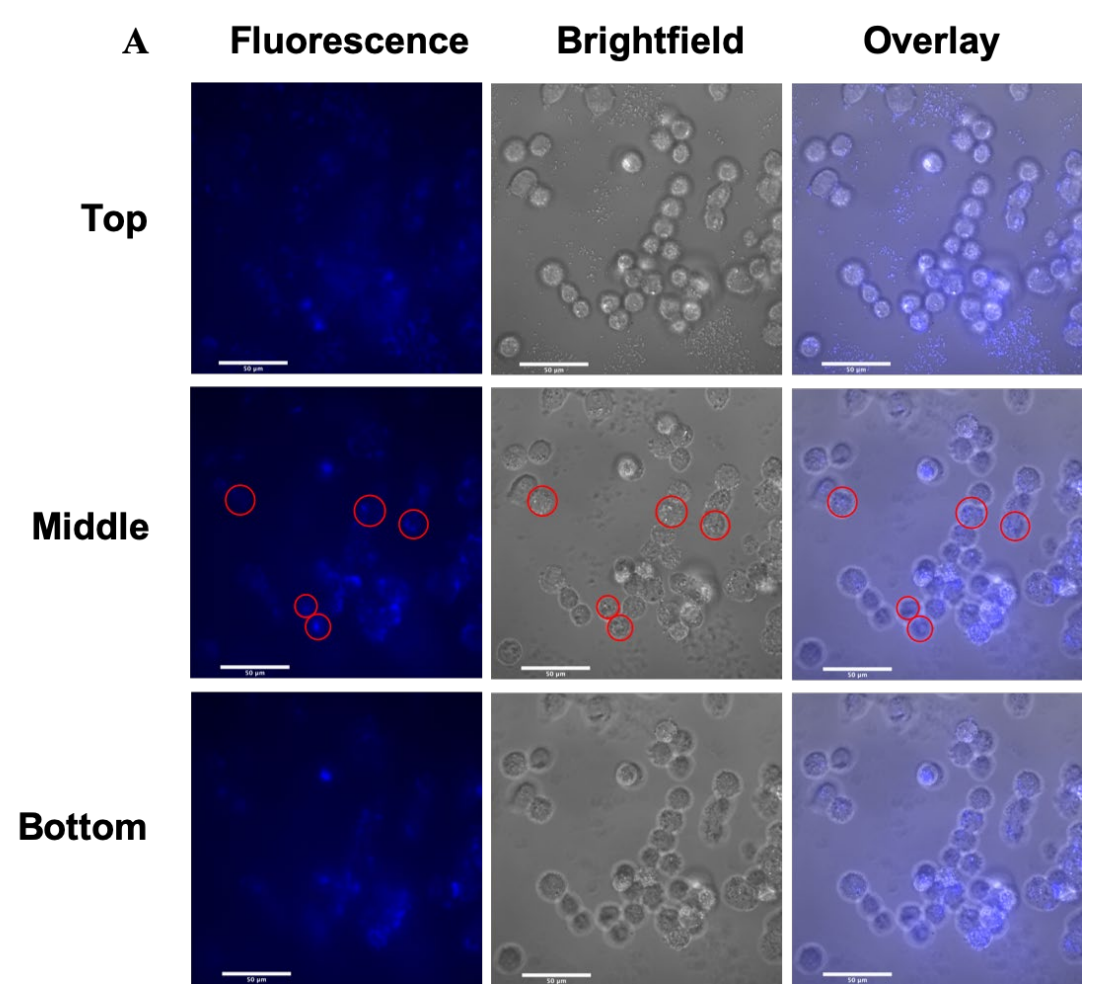




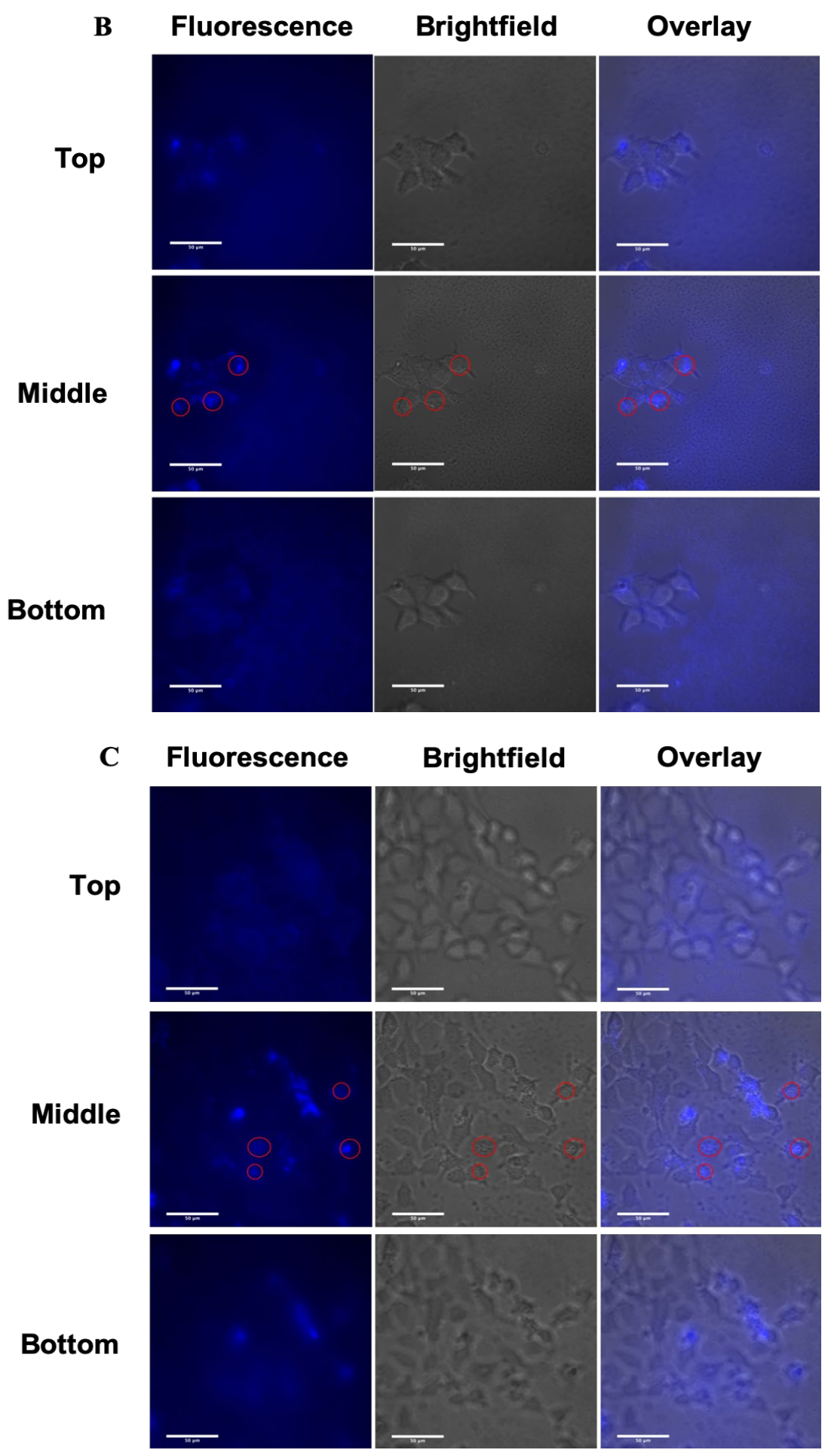

Figure 4. Fluorescent microscope images of (A) MDA-MB-231, (B) MCF-7, and (C) MCF-10A cells treated with ITO NPs for 24 hours. Red circles highlight the presence of ITO NPs in the cellular cytoplasm. Clearly, from the Top and Bottom images, the emitted fluorescence could not be clearly observed. However, the Middle images which represent the inner spaces of the cells, display a strong fluorescence, indicating ITO NPs were internalized by the cells. The scale bar with white colour represents a length of $50 \mu \mathrm{m}$. 


\subsection{In-Vitro CT imaging}

X-ray CT is a very extensively used diagnostic imaging modality due to its high resolution and deep tissue penetration. Therefore, a therapeutic agent with the capability for CT imaging will be highly beneficial and in demand for advanced medical applications. We have demonstrated the capability for anatomical contrast enhancement of ITO NPs using CT, and the results are presented in Figure 3. As can be seen, the ITO NPs exhibited signal enhancement as the CT values in Hounsfield units (HU) linearly increased with increasing concentration of the ITO NPs with a slope of $25.5 \mathrm{HU} \mathrm{L} / \mathrm{g}$. Indeed, several studies have shown CT values of commercial iobitridol with slopes in a range of 25 to $27 \mathrm{HU} \mathrm{L/g.}{ }^{36,56-57}$ The results indicated that ITO NPs are comparable to iobitridol and could be potentially applied as a contrast agent for application in CT imaging. In addition, as an evidence, Dong's team ${ }^{57}$ developed their nanomaterial with a relative lower CT value around $24 \mathrm{HU} \mathrm{L/g} \mathrm{comparing} \mathrm{with} \mathrm{the} \mathrm{commerical} \mathrm{iobitridol} \mathrm{and} \mathrm{our} \mathrm{nanomaterial,} \mathrm{but} \mathrm{also} \mathrm{demonstrated} \mathrm{in-vivo} \mathrm{CT}$ images with clear contrast enhancement.

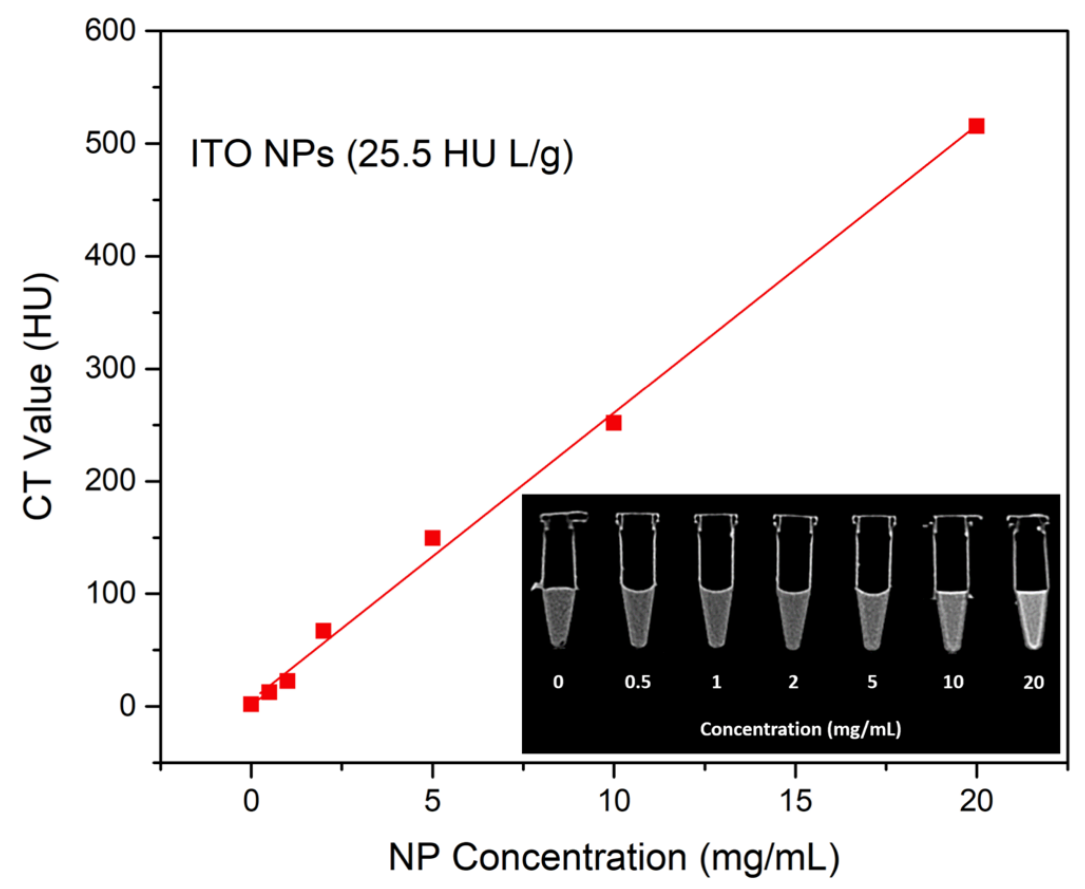

Figure 5. CT value as a function of ITO NP concentration in aqueous solution.

(Figure has been reorganized with higher resolution)

Inset: CT reconstruction images of the ITO NPs with concentrations from 0 to $20 \mathrm{mg} / \mathrm{mL}$ that were imaged around 30 minutes after being placed on the patient couch. 


\subsection{ITO NPs selectively promote intracellular ROS generation in MDA-MB-231 and MCF-7 cancer cells,}

but scavenge the exceeded intracellular ROS in MCF-10A normal cells

To study the effects of the ITO NPs on intracellular ROS generation/scavenging in malignant and nonmalignant cells, the MDA-MB-231 and MCF-7 breast cancer cells, and MCF-10A non-malignant breast cells were exposed to ITO NPs with a concentration of $50 \mu \mathrm{g} / \mathrm{mL}$ for 24 hours, with $\mathrm{H}_{2} \mathrm{O}_{2}$ used as an additional ROS source and NAC used as a ROS scavenger. ROS production/scavenging mediated by $50 \mu \mathrm{g} / \mathrm{mL}$ of ITO NPs was assessed by $\mathrm{H}_{2}$ DCF-DA staining ${ }^{58}$ in MDA-MB-231, MCF-7, and MCF-10A cells, and they were then measured by flow cytometry. The flow cytometric data and quantitative results are displayed in Supporting Figure S9 and Figure 6, respectively. Figure 6(A-B) shows that ITO NPs induced very significant positive changes in ROS generation comparing to the untreated control samples in both MDA-MB-231 and MCF-7 cells, while the ITO NP induced ROS generation could be scavenged by NAC in both types of cancer cells with concentrations of $0.5 \mathrm{mM}$ and $5 \mathrm{mM}$, respectively. To be noted, here we found once the concentration of the added NAC exceeding $0.5 \mathrm{mM}$ in MDA-MB-231 cells would result in a majority of cell death, and the expected scavenging effect from NAC would not be clearly observed; moreover, if the concentration of the added NAC was lower than $5 \mathrm{mM}$ in MCF-7 cells, no significant scavenging effect can be observed (Data not shown).Therefore, in this study, we used $0.5 \mathrm{mM}$ and $5 \mathrm{mM}$ as the optimal concentrations of NAC for MDAMB-231 and MCF-7, respectively. In contrast, the results shown in Figure 6(C) demonstrate that ITO NPs reduced the intracellular ROS levels in both the presence and the absence of $\mathrm{H}_{2} \mathrm{O}_{2}(0.5 \mathrm{mM})$, which.NAC (5 $\mathrm{mM}$ ), presented the same characteristic in MCF-10A cells, suggesting that our ITO NPs exhibited the ROS scavenging behaviour like NAC does. Since NAC is a well-known antioxidant, our experimental results indicated that the engineered ITO NPs can be a potential antioxidant to scavenge the exceeding intracellular ROS level induced by $\mathrm{H}_{2} \mathrm{O}_{2}$. 

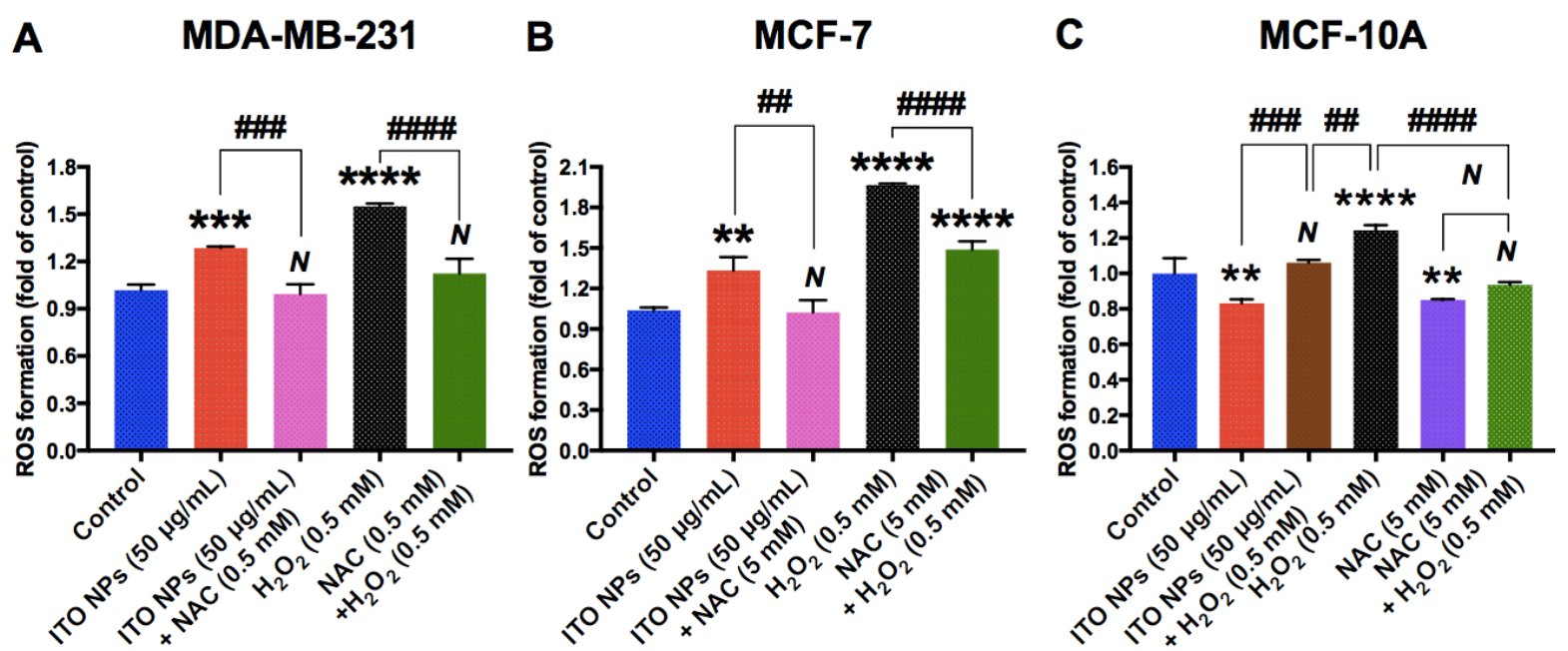

Figure 6. ITO NPs mediated production or scavenging of the intracellular ROS in MDA-MB-231, MCF-7, and MCF-10A cells. (A) and (B) Quantitative results of ITO NP induced generation of intracellular ROS in breast cancer MDA-MB-231 and MCF-7 cells, respectively. (C) Quantitative results of ITO mediated prevention of intracellular ROS in normal MCF-10A breast cells. The $*$ indicates $p<0.05, * *$ indicates $p<0.01, * * *$ indicates $p<0.001$, and $* * * *$ indicates $p<0.0001$ for the comparison with the untreated control. \#\# indicates $p<0.01$, \#\#\# indicates $p<0.001$, and \#\#\#\# indicates $p<0.0001$ for the comparison between the corresponding treatments $(\mathrm{N}=$ not significant). Note: In $(\mathrm{A}),(\mathrm{B})$, and $(\mathrm{C})$, the different colours represent different treatments, and the change in the DCF-fluorescent intensity represents the change in the intracellular ROS level in MDA-MB-231, MCF-7, and MCF-10A cells, respectively. All the presented quantitative results were quantified from the obtained flow cytometric data displayed in Supporting Figure S9.

(Figure has been reorganized with higher resolution, and is moved forward to the discussion of mechanism)

It is meaningful to understand the possible mechanisms explaining how the ITO NPs mediate the intracellular ROS generation or scavenging. Although the exact mechanisms of the ITO NP-mediated ROS induction are still unknown, there are a number of studies that have demonstrated that metal oxide NPs are able to induce ROS generation in cancer cells. ${ }^{14-18,30,59-60}$ In addition, ITO NPs have also been reported to be able to promote the production of intracellular ROS in A549 human lung adenocarcinoma cells. ${ }^{61}$ On the basis of our results, we postulate that the ITO NPs contain abundant oxygen defects and may have mixed $\mathrm{In}^{+2} / \mathrm{In}^{+3}$ valence states. These characteristics were similar to the properties of $\mathrm{CeO}_{2} \mathrm{NPs}^{32,}{ }^{31}$ and thus, we assume that the ITO NPs may possibly present the same oxidative mechanism, SOD-like activity, ${ }^{62-65}$ which $\mathrm{CeO}_{2} \mathrm{NPs}$ present for promoting ROS generation in cancer cells. Therefore, we propose the following sequential chemical reactions as the possible mechanisms for the generation of ROS activated by the ITO NPs.

$$
\mathrm{In}^{2+}+\mathrm{O}_{2} \rightarrow \mathrm{In}^{3+}+\mathrm{O}_{2}^{-}
$$




$$
\mathrm{O}_{2}{ }^{-}+\mathrm{O}_{2}{ }^{-}+2 \mathrm{H}^{+} \rightarrow \mathrm{O}_{2}+\mathrm{H}_{2} \mathrm{O}_{2}
$$

It is known that cancer cells have higher ROS level and are relative acidic, thus, through the metal property of ITO material, the ITO NPs may exhibit heterogenous Fenton-like mechanism ${ }^{66}$ to generate more active ROS, such as hydroxyl radical.

$$
\mathrm{H}_{2} \mathrm{O}_{2}+\mathrm{In}^{3+} \rightarrow \mathrm{In}^{2+}+\mathrm{OH}^{-}+\mathrm{OH}^{\cdot}
$$

Although the possible mechanisms were proposed, more parameters need to be further investigated in order to probe the actual mechanism of the ITO NP induced ROS generation.

In regard to the mechanism for the ROS reduction mediated by the ITO NPs in normal MCF-10A cells, on the basis of the demonstrated results, we hypothesize that our ITO NPs may possess catalase-like activity also in a similar way to cerium oxide NPs, ${ }^{62,64,67}$ so we assume the chemical reactions that represent the possible mechanism for the ROS scavenging mediated by the synthesized ITO NPs as follows:

First, one molecule of $\mathrm{H}_{2} \mathrm{O}_{2}$ is adsorbed onto the surface of $\operatorname{In}_{2} \mathrm{O}_{3}$ (Equation (1)), and the adsorbed $\mathrm{H}_{2} \mathrm{O}_{2}$ subsequently reacts to $\mathrm{In}^{3+}$ with oxygen vacancy $\left(\mathrm{V}_{0}\right)$, reducing it to $\mathrm{In}^{2+}$ and yielding protons, molecular oxygen, and oxygen vacancy $\left(\mathrm{V}_{0}\right)$ (Equation(2)). The $\mathrm{In}^{2+}$ with presence of oxygen vacancy could then react with molecular oxygen or $\mathrm{H}_{2} \mathrm{O}_{2}$ to form the initial $\mathrm{In}^{3+}$ state, and release $\mathrm{H}_{2} \mathrm{O}$ (Equation (3) and (4)).

$$
\begin{aligned}
& \mathrm{H}_{2} \mathrm{O}_{2(\text { aq) }}+\mathrm{In}_{2} \mathrm{O}_{3(\mathrm{~s})} \rightarrow \mathrm{H}_{2} \mathrm{O}_{2(\text { ads })}+\mathrm{In}_{2} \mathrm{O}_{3(\mathrm{~s})} \\
& \mathrm{H}_{2} \mathrm{O}_{2(\text { ads })}+2 \mathrm{In}^{3+}{ }_{(\mathrm{aq})}+\mathrm{V}_{0} \rightarrow \mathrm{O}_{2(\mathrm{~g})}+2 \mathrm{H}^{+}{ }_{\text {(aq) }}+2 \mathrm{In}^{2+}{ }_{(\mathrm{aq})}+\mathrm{V}_{0} \\
& \mathrm{H}_{2} \mathrm{O}_{2(\text { (ads })}+2 \mathrm{H}^{+}{ }_{(\mathrm{aq})}+2 \mathrm{In}^{2+}{ }_{(\mathrm{aq})}+\mathrm{V}_{0} \rightarrow 2 \mathrm{H}_{2} \mathrm{O}_{(\mathrm{l})}+2 \mathrm{In}^{3+}{ }_{(\mathrm{aq})}+\mathrm{V}_{0} \\
& \mathrm{O}_{2(\mathrm{~g})}+4 \mathrm{In}^{2+}{ }_{(\mathrm{aq})}+2 \mathrm{~V}_{0} \rightarrow 4 \mathrm{In}^{3+}{ }_{(\mathrm{aq})}
\end{aligned}
$$

Although we have demonstrated that exploiting a reducing atmosphere for synthesis of ITO nanomaterials could produce ITO NPs with catalase-like property, there are still factors such as intracellular $\mathrm{pH}$ conditions could possible affect the catalase-like property of ITO NPs. Therefore, to explore the complete mechanism of the ROS reduction that activated by the ITO NPs, further studies in molecular level on both materials and cells are needed.

In this study, the overall data demonstrated that the generation and prevention of oxidative stress in MDA-MB-231 and MCF-7 tumor cells and normal MCF-10A cells were well controlled by the mediation of 
the synthesized ITO NPs through a possible triple-catalytic approach, and a conclusive figure of the postulated mechanisms is illustrated in Figure 7.

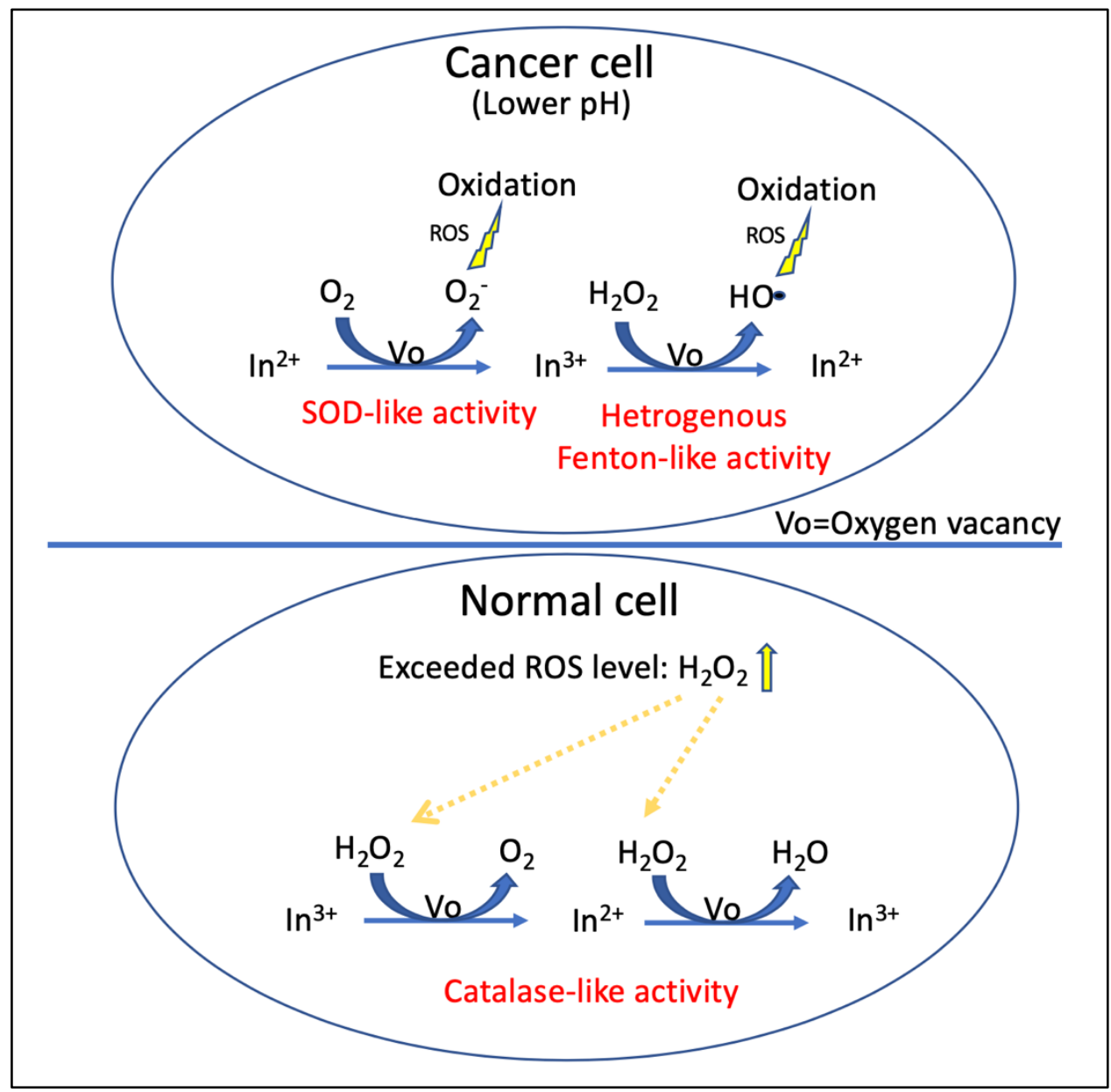

Figure 7. Conclusive illustration of the postulated ITO NP- mediated ROS generation and scavenging mechanisms.

\subsection{ITO NP-mediated intracellular ROS levels play a vital role in apoptosis in MDA-MB-231 and MCF-7} cells, but offer cell protection from ROS-induced damage in MCF-10A cells

It is well known that, when the ROS levels exceed the antioxidative capability of the cell, the cell undertakes an imbalanced oxidative stress and could go through different cell death pathways, leading to cell death, ${ }^{4}$ and one of the cell death pathways can be ROS-induced apoptosis. ${ }^{1}$ Therefore, to investigate the induction of apoptosis in MDA-MB-231 and MCF-7 cells and the promotion of cell-protective effects in MCF10A cells, which were associated with the ITO NP-mediated ROS generation and scavenging, NAC was used as a ROS scavenger for the negative control samples, while $\mathrm{H}_{2} \mathrm{O}_{2}$ was used as an additional source of ROS for the positive control samples. The fluorescent dyes, 7-AAD and Alexa-488-conjugated Annexin-V were used to stain the MDA-MB-231, MCF-7, and MCF-10A cells after 24 hours of exposure to ITO NPs, and the data 
were measured by flow cytometry. Figure 8A shows the quantitative results of cell death for the measured cells, where the live, early apoptotic and late apoptotic including dead populations were defined on the basis of the measured 7-AAD fluorescence intensity using the method developed by Zembruski et al. ${ }^{68}$ The analysed forward scatter versus 7-AAD dot plots for MDA-MB-231, MCF-7, and MCF-10A cells with and without treatments are displayed in Supporting Figure S10. As can be seen in Figure 8A, ITO NPs significantly increased apoptosis in MDA-MB-231 and MCF-7 cancer cells. When the cells were exposed to both ITO NPs and the ROS scavenger NAC, the apoptosis was significantly reduced to levels close to those of the untreated control samples. The results directly reflected the results of ROS generation that we previously discussed, showing that apoptosis in cancer cells increased with increasing intracellular ROS generation. This indicated that the apoptosis of cancer cell induced by the ITO NPs was directly associated with the promotion of intracellular ROS induced by the ITO NPs. In addition, apoptotic populations in normal MCF-10A cells exposed to ITO NPs alone and NAC alone, were slightly lower than those in the untreated control. Moreover, MCF-10A cells exposed to addition of both ITO NPs and the ROS source $\mathrm{H}_{2} \mathrm{O}_{2}$ even presented a significant decrease in apoptosis comparing with those solely exposed to $\mathrm{H}_{2} \mathrm{O}_{2}$, while the cells exposed to the addition of both $\mathrm{NAC}$ and $\mathrm{H}_{2} \mathrm{O}_{2}$ presented the same results. Taking the reduction of apoptotic populations and the ROS results into account, the apoptosis in MCF-10A cells decreased with decreasing intracellular ROS levels in both the absence and the presence of $\mathrm{H}_{2} \mathrm{O}_{2}$, indicating that the apoptosis could be reduced by both ITO NPs and NAC, and were directly associated with the reduction of the intracellular ROS level by both ITO NPs and NAC. Interestingly, the synthesized ITO NPs did not present any protective effect when exposed with $\mathrm{H}_{2} \mathrm{O}_{2}$ in both malignant MCF-7 and MDA-MB-231 cells. In fact, the apoptosis rate even increased significantly when MCF-7 cells were treated together with ITO NPs and $\mathrm{H}_{2} \mathrm{O}_{2}$ comparing with the solely $\mathrm{H}_{2} \mathrm{O}_{2}$ treatment.

To make sure the synthesized ITO NPs can induce apoptosis in both malignant MCF-7 and MDA-MB231 cells, but reduce that in normal MCF-10A cell, Annexin-V binding is used. Annexin-V binding is wildly used for detection of apoptosis, ${ }^{69}$ where a positive change in Annexin-V binding intensity indicates an increase in cell apoptosis. Figure 8B displays the flow cytometric results of the relative Annexin-V fluorescein binding intensity for various treatments. Significantly, apoptosis was induced by exposure to ITO NPs, but was reduced by the addition of NAC in both MDA-MB-231 and MCF-7 cancer cells, while, a decreased rate of apoptosis was mediated by the exposure of ITO NP and by the addition of NAC in both the absence and the presence of $\mathrm{H}_{2} \mathrm{O}_{2}$ in normal MCF-10A cells. Consequently, the results of the Annexin-V binding assay present the same trend as the results of 7-AAD staining, confirming that ITO NP-induced production of intracellular ROS can promote apoptosis in both MDA-MB-231 and MCF-7 breast cancer cells. The Annexin-V results also clearly 
demonstrate that the ITO NP-mediated prevention of intracellular ROS can reduce the oxidative stress induced apoptosis occurring in MCF-10A normal breast cells.

A

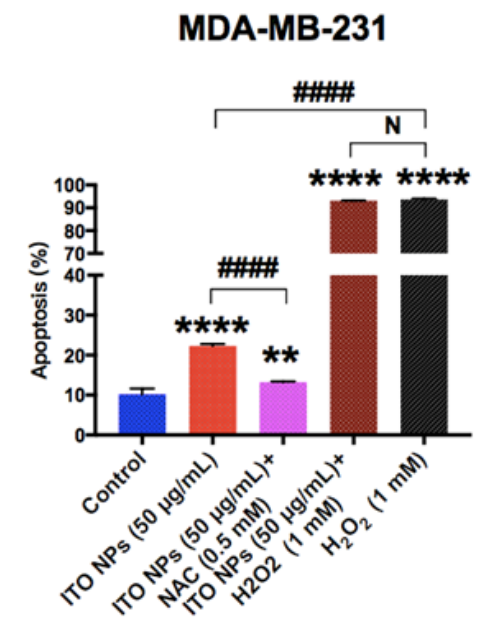

B

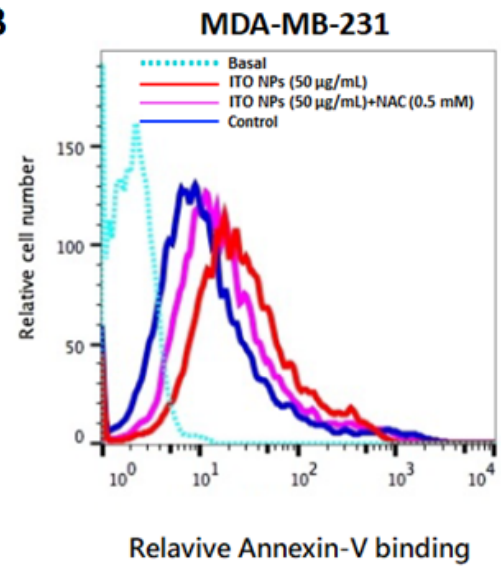

MDA-MB-231

Relavive Annexin- $\mathrm{V}$ binding
MCF-7

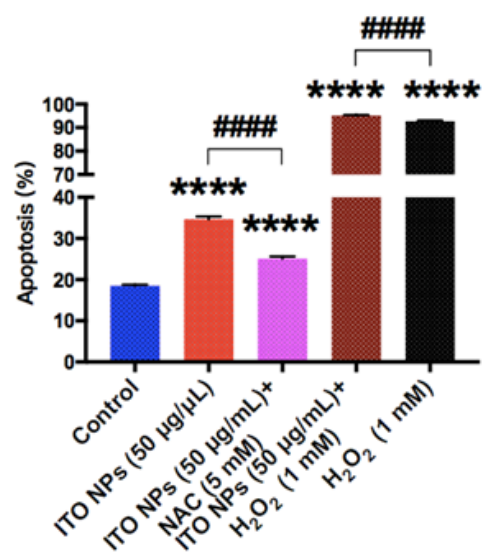

MCF-7

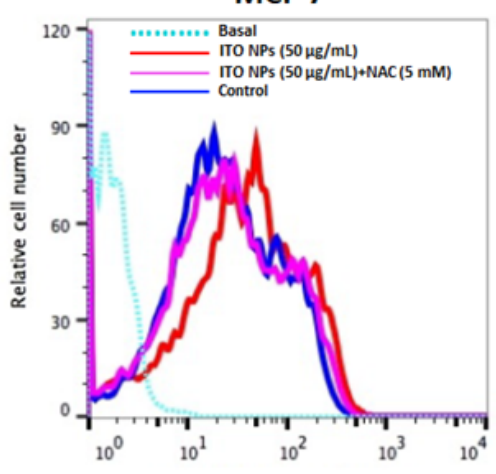

Relavive Annexin-V binding
MCF-10A
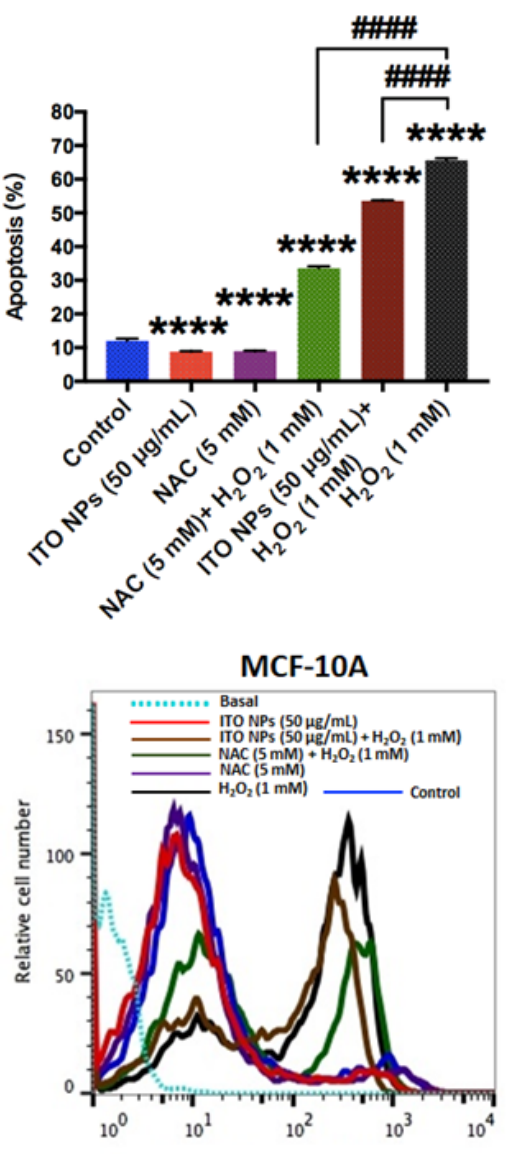

Relavive Annexin-V binding

Figure 8. ITO NPs mediated cell apoptosis in MDA-MB-231, MCF-7, and cell protection in MCF-10A cells.

(A), Analysed quantitative results based on the 7-AAD binding intensity as detected by flow cytometry for the apoptosis induced by the treatments consisting of ITO NPs alone, ITO NPs with NAC, ITO NPs with $\mathrm{H}_{2} \mathrm{O}_{2}$, and $\mathrm{H}_{2} \mathrm{O}_{2}$ alone in MDA-MB-231 (left) and in MCF-7 (middle) cell lines, and those induced by the treatments with ITO NPs, NAC, $\mathrm{H}_{2} \mathrm{O}_{2}$, ITO NPs with $\mathrm{H}_{2} \mathrm{O}_{2}$, and NAC with $\mathrm{H}_{2} \mathrm{O}_{2}$ in MCF-10A (right) cell line. Data was shown in combination of early and late apoptotic (dead) cells. The $* *$ indicates $p<$ 0.01 , and $* * * *$ indicates $p<0.0001$ for the comparison with the untreated control. The \#\#\#\# indicates $p<0.0001$ for the comparison between the corresponding treatments. $\mathrm{N}$ represents not statistically significant; (B), Flow cytometric results on Annexin-V fluorescein binding intensity to indicate the apoptosis induced by the treatments with ITO NPs alone and ITO NPs with NAC in MDA-MB-231 (left) and in MCF-7 (middle), and that induced by the treatments with ITO NPs, NAC, $\mathrm{H}_{2} \mathrm{O}_{2}$, ITO NPs with $\mathrm{H}_{2} \mathrm{O}_{2}$, and NAC with $\mathrm{H}_{2} \mathrm{O}_{2}$ in MCF-10A (right) cell lines. Note: In Figure 8B, the different colours represent different treatments (with "Basal" representing the untreated control without any staining), and the change in the Annexin-V binding intensity represents the change in the rate of cell apoptosis. 


\subsection{ITO NPs selectively kill MDA-MB-231 and MCF-7 cells while protecting MCF-10A cells}

The clonogenic assay ${ }^{70}$ was used to further investigate the cytotoxicity of the ITO NPs towards MDAMB-231, MCF-7, and MCF-10A cells. The surviving fractions of MDA-MB-231, MCF-7, and MCF-10A cells after 24 hours of treatment with ITO NPs at a concentration of $50 \mu \mathrm{g} / \mathrm{mL}$, as determined using clonogenic assay, are illustrated in Figure 9(A-B). For both MDA-MB-231 and MCF-7 malignant cells, the surviving fractions were significantly decreased, with less than $10 \%$ and around $30 \%$, respectively, showing very high mortality in malignant cells. In contrast, the surviving fraction of MCF-10A cells was slight increased after treatment with ITO NPs compared with the untreated control sample, implicating that ITO NPs are able to support the cell proliferation. Moreover, the surviving fraction of MCF-10A cells treated with both ITO NPs and $\mathrm{H}_{2} \mathrm{O}_{2}$ was even significantly higher than the cells treated with $\mathrm{H}_{2} \mathrm{O}_{2}$ alone, suggesting that ITO NPs protected the cells from an increased external oxidative stress. These results further supported the proposition that ITO NPs could selectively mediate the production or prevention of exceeded intracellular ROS, and promote or suppress cellular apoptosis, finally resulting in cell death or in cell protection for malignant and non-malignant cells, respectively. In addition, our group have investigated the cytotoxicity of the as-prepared ITO NPs on different animal non-malignant and malignant cell lines - Madin-Darby Canine Kidney (MDCK) cells and GS-9L rat glioma cells using clonogenic assay, and the results also demonstrated that the ITO NPs are highly toxic towards malignant 9L cells with a surviving fraction less than $6 \%$, but are harmless towards normal MDCK cells (Data shown in Supporting Figure S13). The results implicated that the ITO NPs are highly selective towards a wide range of malignant and non-malignant cells. 
MDA-MB-231

MCF-7

MCF-10A
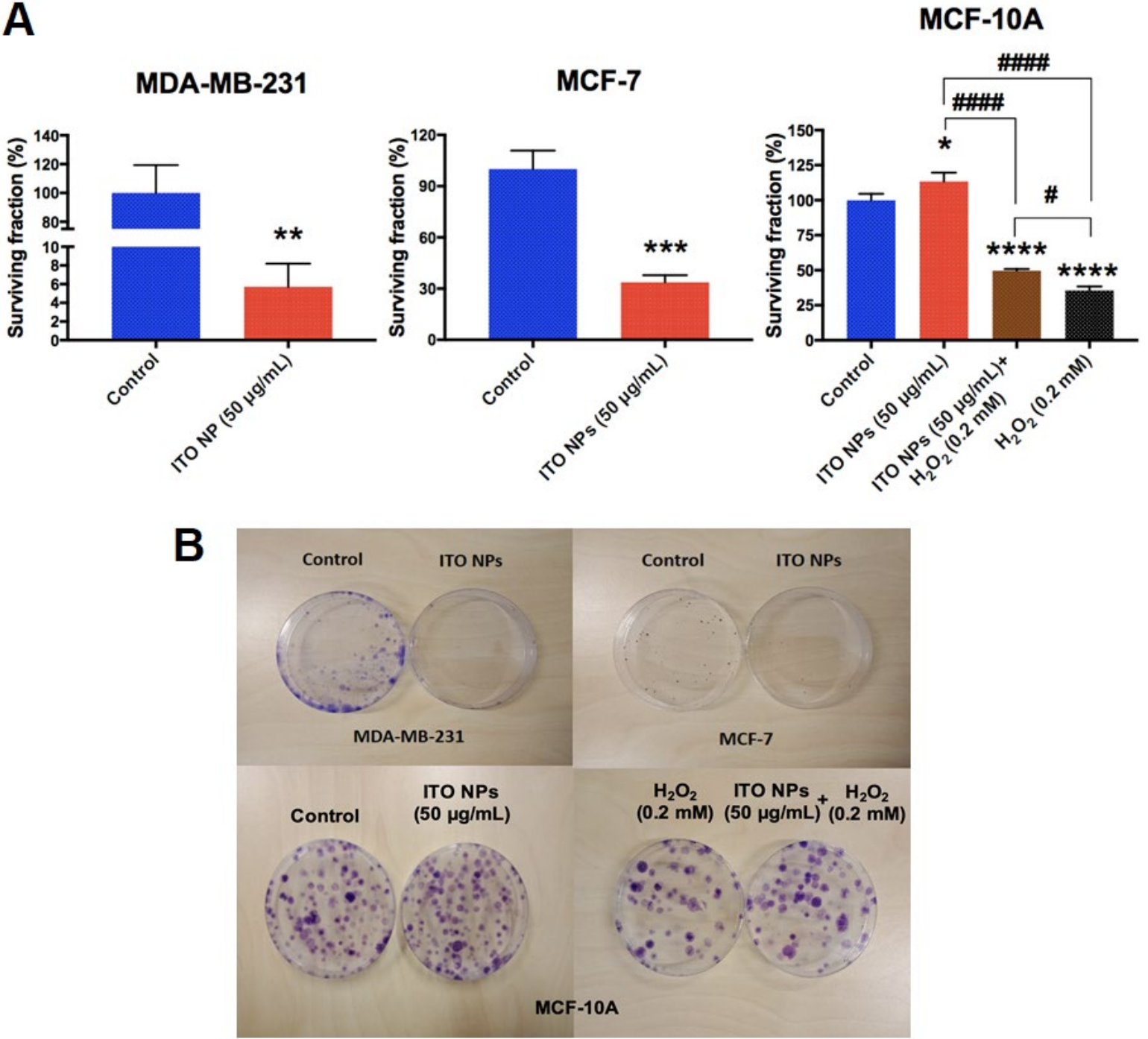

Figure 9. Clonogenic results of ITO NPs in MDA-MB-231, MCF-7, and MCF-10A cells. (A), Quantitative clonogenic results for MDA-MB-231 (left) and MCF-7 cells (middle) treated with and without ITO NPs, and for MCF-10A cells (right) without treatment and treated with ITO NPs, $\mathrm{H}_{2} \mathrm{O}_{2}$, and ITO NPs with $\mathrm{H}_{2} \mathrm{O}_{2}$. The concentration of ITO NPs for the treatment was 50 $\mu \mathrm{g} / \mathrm{mL}$, and "Control" represents the samples without treatment. * indicates $p<0.05, * *$ indicates $p<0.01, * * *$ indicates $p<$ 0.001 , and $* * * *$ indicates $p<0.0001$ for the comparison with the untreated control. \# indicates $P<0.05$, and \#\#\#\# indicates $p<$ 0.0001 for the comparison between the corresponding treatments; (B), Photographs of colony formation with and without treatment by ITO NPs in MDA-MB-231 (upper-left) and in MCF-7 cells (upper-right). MCF-10A (bottom) without treatment and treated with ITO NPs alone, $\mathrm{H}_{2} \mathrm{O}_{2}$ alone, and $\mathrm{H}_{2} \mathrm{O}_{2}$ with ITO NPs. The concentration for the ITO NP treatment was $50 \mu \mathrm{g} / \mathrm{mL}$. (Figure has been reorganized with higher resolution) 


\section{CONCLUSIONS}

In this study, we provided the first evidence that nano-engineered ITO NPs can selectively mediate the generation and reduction of intracellular ROS in malignant MDA-MB-231and MCF-7, and non-malignant MCF-10A breast cells. The generated oxidative stress can further promote cancer cell apoptosis and results in a high cell mortality in both MDA-MB-231 and MCF-7 cells. In contrast, for MCF-10A cells, ITO NPs can promote scavenging of intracellular ROS, which suppresses the cell apoptosis and further supports cell proliferation in both the absence and the presence of $\mathrm{H}_{2} \mathrm{O}_{2}$. An important practical conclusion for future nanooxide materials toxicity studies is the fact that the toxicity effect can be detrimentally different depending on the type of studied cells: malignant or non-malignant, and biased conclusions could be made regarding the materials toxicity if malignant cells only are used in the tests. In addition, the ITO NPs feature attractive multimodal imaging properties such as strong fluorescence and comparable anatomical contrast enhancement capability for CT imaging, which makes this nanomaterial a promising theranostic agent for cancer treatment and also gives it potential for treatment of other oxidative stress related conditions. The conclusion is highlighted as shown in Figure 10.

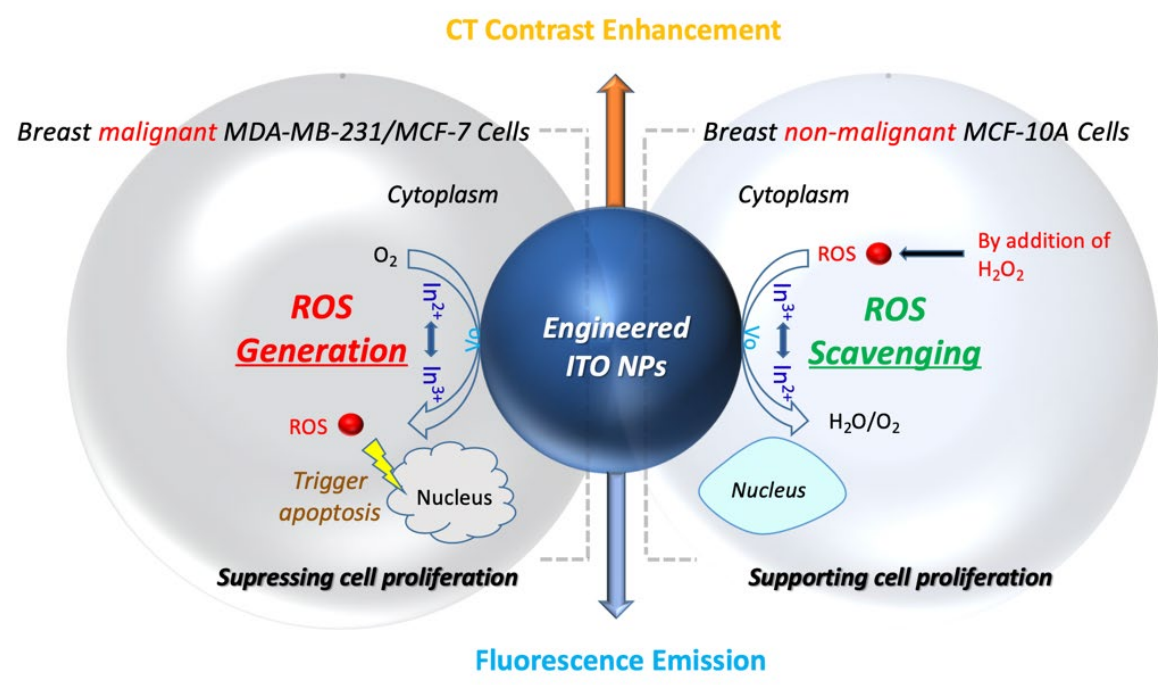

Figure 10. Illustration on the theranostic feature and selective mechanism of the engineered ITO NPs for breast cancer treatment. 


\section{METHODS}

\section{Materials}

Indium metal $(>99.8 \%)$, anhydrous tin tetrachloride (>99.9\%), ammonium hydroxide (28-30\%), $\mathrm{H}_{2}$ DCF-DA, N-acetyl-L-cysteine (NAC), hydrocortisone, cholera toxin, crystal violet solution $(2.3 \%$ crystal violet, $0.1 \%$ ammonium oxalate, $20 \%$ ethyl alcohol), denatured ethanol, and reagent-grade ethanol were all purchased from Sigma-Aldrich (Australia). Hydrochloric acid (36\%) was from UNIVAR (Australia). 7 Amino-actinomycin D (7-AAD) and Annexin-V, Alexa Fluor ${ }^{\mathrm{TM}} 488$ conjugate were from Thermo Fisher Scientific (Australia). Dulbecco's Modified Eagle Medium (DMEM), DMEM/F-12 medium, fetal bovine serum (FBS), horse serum, insulin, epidermal growth factor (EGF), penicillin, streptomycin, Dulbecco's phosphate-buffered saline (DPBS), phosphate-buffered Saline (PBS), and trypsin ethylenediaminetetracacetic acid (trypsin-EDTA) were from Life Technologies (Australia).

\section{Synthesis of ITO NPS}

ITO NPs were synthesized as follows: First, in a three-neck flask, $5 \mathrm{~g}$ of metal indium (0.044 mmol) was dissolved in $20 \mathrm{~mL}$ of $36 \%$ hydrochloric acid with magnetic stirring at $70^{\circ} \mathrm{C}$. When fully dissolved, $0.514 \mathrm{~mL}$ $(0.0045 \mathrm{mmol})$ of anhydrous tin tetrachloride was added, and the solutions were allowed to mix by a controlled magnetic stirring and cool to room temperature. Once room temperature was reached, 30\% ammonium hydroxide was added to the flask, and testing the $\mathrm{pH}$ value until it reached around 8 , and a white precipitate precursor was obtained. The precipitate precursor of ITO was then aged for 24 hours, collected by filtration, and then washed with deionized water. After washing, the precursor of ITO or so-called indium tin hydroxide (ITOH) was dried for 12 hours at $353 \mathrm{~K}$. The dried sample was annealed in a horizontal LABEC tube furnace at $673 \mathrm{~K}$ for 1.5 hours under a reducing atmosphere (5\% hydrogen mixed with argon gas).

\section{Characterization of ITO NPS}

The crystalline structures of the nanopowders were characterized using an Enhanced Mini-Materials Analyzer (EMMA) X-ray diffractometer (XRD) from GBC Scientific (Australia). The XRD pattern of the ITO NPs was acquired at room temperature with $\mathrm{Cu} \mathrm{K \alpha}$ radiation $(\lambda=1.5418 \AA)$ at $40 \mathrm{kV}$ and $25 \mathrm{~mA}$ in the range of $20^{\circ}$ to $65^{\circ}$ at a scanning rate of $2^{\circ} \mathrm{min}^{-1}$. A JEOL (Akishima) JEM 2010 transmission electron microscope (TEM), operated at an accelerating voltage of $200 \mathrm{kV}$, was used to analyse the particle morphology. Highresolution TEM images were captured using a JEM-ARM200F atomic resolution microscope fitted with a 
Centrino SDD $100 \mathrm{~mm}^{2}$ detector (JEOL). The fast Fourier transform (FFT) image was obtained using Gatan Digital Micrograph software. The samples were prepared on carbon-coated copper grids, and the image processing was carried out using Gatan Digital Micrograph software (USA). The elemental composition (purity) of the ITO NPs was determined using a JSM7500FA cold field emission gun scanning electron microscope equipped with an X-Flash $401010 \mathrm{~mm}^{2}, 127 \mathrm{eV}$ SDD energy dispersive X-ray detector (Bruker, USA) with an accelerating voltage of $20 \mathrm{kV}$. Surface features, including the chemical composition and surface defects of the ITO nanopowders, were evaluated using X-ray photoelectron spectroscopy (XPS), which was conducted using a SPECS PHOIBOS 100 Analyzer installed in a high-vacuum chamber with the base pressure below $10^{-8}$ mbar. The X-ray excitation source was provided by Al K $\alpha$ radiation with a photon energy of 1486.6 $\mathrm{eV}$ at the high voltage of $12 \mathrm{kV}$ and power of $120 \mathrm{~W}$. The binding energy scale of all measurements was calibrated using the $\mathrm{C} 1 \mathrm{~s}$ peak at $284.8 \mathrm{eV}$. All XPS data was analysed using CasaXPS 2.3.15 software. The hydrodynamic diameter of the ITO nanoparticles suspended in PBS was determined by dynamic light scattering (DLS) using a Malvern (UK) Zetasizer APS2000. The ITO NPs were first dispersed in PBS at the concentration of $1 \mathrm{mg} / \mathrm{mL}$ and sonicated for 2 hours using a sonication bath (Branson 3800, Ultrasonics Corporation, USA), and then a diluted final concentration of $50 \mu \mathrm{g} / \mathrm{mL}$ was used to perform the DSL experiments in three independent measurements at room temperature.

\section{Flow cytometry for determination of cellular uptake of ITO NPS}

Suspensions of ITO NPs were added to MDA-MB-231, MCF-7, and MCF-10A cells, with a final concentration of $50 \mu \mathrm{g} / \mathrm{mL}$. After treatment for 24 hours, the cells were harvested using $0.05 \%$ trypsin-EDTA, and then centrifuged and washed twice with PBS. The individual cell pellets were resuspended in $500 \mu \mathrm{L}$ of PBS, transferred into $5 \mathrm{~mL}$ polystyrene flow tubes, and data acquired using a BD-LSR-II flow cytometer. The intensity of the forward scattered (FSC) light is proportional to the size and surface area of the cell, while the intensity of the side scattered (SSC) light is proportional to cell granularity and complexity, so that this technique can be used to determine cellular internalization of NPs. FlowJo software (Tree Star, USA) was used to analyse the acquired data and to determine the relative degree of cellular internalization of the ITO NPs.

\section{Fluorescence microscopy}

Fluorescent microscopy was used to examine whether the fluorescence-emitted ITO NPs were inside the cells. First, the cells were seeded on a $\mu$-Slide 8 Well Glass Bottom (ibidi, Germany) chamber slide, and were allowed to attach to the surface for 24 hours before the addition of ITO NPs at a concentration of $50 \mu \mathrm{g} / \mathrm{mL}$. 
After 24 hours of exposure to the ITO NPs, the cells were washed with PBS, and were then proceeded to imaging. Briefly, slides of the live cells were imaged and the images captured using a Leica (Germany) DMi8 Fluorescent Microscope and LAS X software (excitation at $400 \mathrm{~nm}$, emissions collected at 470-550 nm). Under a $63 \mathrm{X}$ oil immersion objective, the cells were imaged along the z-axis from top to bottom with the same intervals, creating a number of z-sections with different strengths of fluorescence emitted from the ITO NPs. Thereafter, the locations of the ITO NPs could be navigated by analysing the z-sections of the cell images. The slice of each individual cell image was analysed using ImageJ software.

\section{Computed tomography $(C T)$}

The capability for anatomical contrast enhancement of the ITO NPs alone was demonstrated using computed tomography (CT). Suspensions of ITO NPs with a range of concentrations from 0 to $20 \mathrm{mg} / \mathrm{mL}$ were placed in $1.5 \mathrm{~mL}$ vials and imaged together using a Toshiba (Japan) Asteion (model TSX-021A) whole body X-ray CT scanner with a $200 \mathrm{~mA}$ tube current, $120 \mathrm{kV}$ tube voltage, $1 \mathrm{~mm}$ slice thickness, and $93 \mathrm{~mm}$ field of view diameter. The CT images were captured using the standard patient image reconstruction algorithms integrated with the scanner.

\section{Cell culture and exposure to ITO NPS}

Human epithelial MDA-MB-231 and MCF-7 breast cancer cells (mammary gland adenocarcinoma cell lines) and human epithelial MCF-10A normal breast cells (mammary gland cell line) were all purchased from the European Collection of Cell Cultures (ECACC). Both types of cancer cells were cultured in DMEM medium supplemented with L-glutamine $(2 \mathrm{mM})$, FBS $(10 \%(\mathrm{v} / \mathrm{v}))$, and penicillin/streptomycin $(1 \%(\mathrm{v} / \mathrm{v}))$ at $37^{\circ} \mathrm{C}$ and $5 \%(\mathrm{v} / \mathrm{v}) \mathrm{CO}_{2} . \mathrm{MCF}-10 \mathrm{~A}$ cells were cultured in DMEM/F-12 medium containing L-glutamine (2 $\mathrm{mM})$, horse serum $(5 \%(\mathrm{v} / \mathrm{v}))$, epidermal growth factor (EGF, $20 \mathrm{ng} / \mathrm{mL})$, hydrocortisone $(0.5 \mathrm{mg} / \mathrm{mL})$, cholera toxin $(100 \mathrm{ng} / \mathrm{mL})$, insulin $(10 \mu \mathrm{g} / \mathrm{mL})$, and penicillin/streptomycin $(1 \%(\mathrm{v} / \mathrm{v}))$ at $37^{0} \mathrm{C}$ and $5 \%(\mathrm{v} / \mathrm{v}) \mathrm{CO}_{2}$. Cells were maintained in T-75 $\mathrm{cm}^{2}$ tissue culture flasks, and subcultured using $0.05 \%$ trypsin-EDTA. At $80 \%$ confluence, cells were transferred into new flasks or into other sized flasks or plates for passaging or experiments as indicated below. For cell passaging, cells were transferred into T-75 $\mathrm{cm}^{2}$ flasks; for measurements of cellular internalization and intracellular ROS, cells were transferred into T-25 $\mathrm{cm}^{2}$ flasks; for evaluation of apoptosis, cells were transferred into 6-well plates; for determination of cell survival and proliferation, cells were first transferred into T-12.5 $\mathrm{cm}^{2}$ flasks, after treatment of ITO NPs, cell were then transferred into $100 \mathrm{~mm}$ Petri dishes (BD Falcon). All flasks and plates with seeded cells were maintained in 
an incubator supplied with $5 \%(\mathrm{v} / \mathrm{v}) \mathrm{CO}_{2}$ at $37^{\circ} \mathrm{C}$. In all experiments, cells were grown until one day before $80 \%$ confluence, prior to exposure to ITO NPs. Cells were exposed to ITO NPs with a total concentration of $50 \mu \mathrm{g} / \mathrm{mL}$ for 24 hours, and then harvested to examine apoptosis, ROS generation, and cytotoxicity. Cells without ITO NP exposure served as controls in each experiment.

\section{Measurement of intracellular ROS}

Generation of intracellular ROS was measured using 2,7-dichlorofluorescein diacetate ( $\left.\mathrm{H}_{2} \mathrm{DCF}-\mathrm{DA}\right)$. In brief, cells were treated with ITO NPs at a concentration of $50 \mu \mathrm{g} / \mathrm{mL}$ for 24 hours. At the end of treatment, cells were typsinized, followed by centrifugation and washing three times with PBS. Afterwards, cells were incubated with $500 \mu \mathrm{L}$ of $40 \mu \mathrm{M} \mathrm{H} \mathrm{H}_{2}$ DCFDA in the dark for 30 minutes, then washed three times with PBS. Cells were then resuspended with $500 \mu \mathrm{L}$ of PBS and transferred into $5 \mathrm{~mL}$ polystyrene tubes. Data was acquired using a LSR-II flow cytometer (excitation at $488 \mathrm{~nm}$, emissions collected with a 515/20 nm bandpass filter), and the relative fluorescent intensity of dichlorofluorescein (DCF) was determined using FlowJo software. In some experiments, ITO NP-induced ROS generation was examined. MDA-MB-231, and MCF-7 cells were preincubated in the absence or presence of $0.5 \mathrm{mM}$ or $5 \mathrm{mM}$ of the ROS scavenger, NAC, respectively for 1 hour prior to ITO NPs addition. In the MCF-10A experiments, ITO NP-mediated ROS scavenging was examined. Cells were incubated with ITO NPs for one hour, and then incubated in the absence or presence of $0.5 \mathrm{mM} \mathrm{H} \mathrm{O}_{2}$, where $\mathrm{H}_{2} \mathrm{O}_{2}$ served as an additional source of ROS. In all experiments, cells incubated with $\mathrm{NAC}$ or $\mathrm{H}_{2} \mathrm{O}_{2}$ alone served as negative or positive control samples, respectively. Cells preincubated with $\mathrm{NAC}$ for 1 hour prior to addition of $\mathrm{H}_{2} \mathrm{O}_{2}$ served as a quality control sample for testing the validation of the experiment.

\section{Evaluation of ROS-induced apoptosis}

ROS-induced apoptosis was measured using Annexin-V and 7-AAD doubling staining. In brief, cells were treated with ITO NPs at a concentration of $50 \mu \mathrm{g} / \mathrm{mL}$ for 24 hours. At the end of treatment, cells were typsinized, centrifuged, and washed once with Annexin- $\mathrm{V}$ binding medium $(\mathrm{NaCl}$ medium containing $5 \mathrm{mM}$ $\mathrm{CaCl}_{2}$ ). Cells were then incubated with Annexin- $\mathrm{V}$ binding medium containing Alexa-488-conjugated Annexin- $\mathrm{V}$ and 7-AAD at room temperature in the dark for 15 minutes. Data were then acquired using a LSRII flow cytometer (excitation at $488 \mathrm{~nm}$, emissions collected with 515/20 nm and 695/40 nm band-pass filters for Annexin-V conjugated Alex 488 and 7-AAD, respectively). The relative fluorescence intensities of Alexa488-conjugated Annexin-V and 7-AAD were examined using FlowJo software. In some MDA-MB-231 and 
MCF-7 experiments, cells were preincubated in the absence or presence of $0.5 \mathrm{mM}$ and $5 \mathrm{mM}$ of NAC, respectively, for 1 hour prior to addition of ITO NPs, where NAC used as a ROS scavenger to assess whether the ITO NP-induced ROS generation was associated with activation of cellular apoptosis. In some MCF-10A experiments, cells were first incubated with ITO NPs for one hour and then incubated in the absence or presence of $0.5 \mathrm{mM} \mathrm{H}_{2} \mathrm{O}_{2}$, where $\mathrm{H}_{2} \mathrm{O}_{2}$ was used as an additional ROS source to assess whether the ITO NP-mediated ROS scavenging behaviour was associated with reduction of cellular apoptosis.

\section{Cell survival and proliferation}

Clonogenic assays were performed to evaluate the cytotoxicity of ITO NPs. MDA-MB-231, MCF-7, and MCF-10A cells were first seeded into T-12.5 $\mathrm{cm}^{2}$ flasks and incubation stopped at one-day before the cells reached $80 \%$ confluence, and then the suspension of ITO NPs was added into the flasks for a total concentration of $50 \mu \mathrm{g} / \mathrm{mL}$ and left for 24 hours. After 24 hours treatment, cells were trypsinised, plated at a cell density range from 400 to 20000 (depending on the cell type) into $100 \mathrm{~mm}$ Petri dishes with $10 \mathrm{~mL}$ complete cell culture medium, and incubated for 15 doubling times at $37^{\circ} \mathrm{C}$ and $5 \%(\mathrm{v} / \mathrm{v}) \mathrm{CO}_{2}$. Colony formation of the cells was terminated by washing with $5 \mathrm{~mL}$ DPBS, and the cell colonies were visualized by staining with a solution of $25 \%(\mathrm{v} / \mathrm{v})$ crystal violet and $75 \%(\mathrm{v} / \mathrm{v})$ ethanol. Cell colonies were counted using optical microscopy, with colonies defined by groups of at least fifty cells. The surviving fraction was obtained by the comparison of the plating efficiency between the control and the treated samples.

\section{Statistical analysis}

Data were presented as the mean \pm standard deviation (SD). Statistical differences between the control and treatments for measurements of ROS generation, cell apoptosis, and the clonogenic results of MCF-10A cells, were evaluated by one-way analysis of variances (ANOVA) paired with Tukey's HSD post-test. Clonogenic results from MDA-MB-231 and MCF-7 cells, as well as the results of cellular internalization of ITO NPs in MDA-MB-231, MCF-7, and MCF-10A cells, were analysed by the Student's t-test with two-tailed calculation, and statistical differences were between the control and treatments. Data analysis was performed using Prism 7 for Mac (GraphPad Software, USA). A value of $p<0.05$ was considered statistically significant.

\section{Disclosure of Potential Conflicts of Interest}

No potential conflicts of interest were disclosed. 


\section{Acknowledgements}

This work was supported by the Institute for Superconducting \& Electronic Materials Australian Institute of Innovative Materials, the Illawarra Health and Medical Research Institute, the Centre for Medical Radiation Physics, and the Electron Microscopy Centre at the University of Wollongong. Furthermore, the authors acknowledge the support from the National Health and Medical Research Council (APP1084994), and the MicroNanofluidics \& Nanobiosensor Research Laboratory at the Griffith University and The University of Wollongong Global Challenges program support. The authors would also like to thank Dr. D. Shi for conducting the XPS measurements, and Dr. T. Silver for her help with editing the manuscrip.

\section{ASSOCIATED CONTENT}

\section{Supporting Information}

\section{Supporting Table S1.}

EDS results for ITO precursors and ITO nanoparticles.

Supporting Figure S1. (This figure has been moved to the main text in Page 5, and the discussion is in Page 4.)

X-ray diffraction pattern, (B) EDS spectrum, (C) TEM image, and (D) HR-TEM image with an inset of corresponding FFT pattern of the synthesized ITO NPs.

\section{Supporting Figure S2.}

Hydrodynamic diameter of ITO NPs suspended in PBS, determined via dynamic light scattering. The concentration of the suspension of ITO NPs is $50 \mu \mathrm{g} / \mathrm{mL}$. (This figure has been moved to the main text in Page 6)

\section{Supporting Figure S1.}

ITO-2 NP induced generation of intracellular ROS in MDA-MB-231 (left), MCF-7 (middle), and MCF-10A cells (right).

\section{Supporting Figure S2.}

High-resolution XPS O 1s spectrum for ITO-2 NPs.

\section{Supporting Figure S3.}

High-resolution XPS spectra of (A) In 3d3/2 of ITO-1 NPs, (B) In 3d3/2 of ITO-2 NPs.

\section{Supporting Figure $\mathrm{S4}$.}

Flow cytometry histograms (A) and (B) show the cellular internalization of ITO NPs through side and forward scattering, respectively, in MDA-MB-231, MCF-7, and MCF-10A cells. Comparisons of cellular internalization between different control and treated samples were quantified and are presented as (C).

\section{Supporting Figure S5.}

Fluorescent images (left), bright field images (middle), and overlay of fluorescence and bright field images (right) of MDA-MB231, MCF-7, and MCF-10A cells without treatment by ITO NPs. 


\section{Supporting Figure S6.}

Fluorescence images (left), bright field images (middle), and overlays of the fluorescence and bright field images (right), with the z-positions analysed through the $17^{\text {th }}, 19^{\text {th }}, 23^{\text {rd }}$, and $25^{\text {th }}$ sections of the MDA-MB-231 cells treated with ITO NPs for $24 \mathrm{~h}$.

\section{Supporting Figure S7.}

Fluorescence images (left), bright field images (middle), and overlays of the fluorescence and bright field images (right), with the z-positions analysed through the $23^{\text {rd }}, 25^{\text {th }}, 28^{\text {th }}$, and 30th sections of MCF-7 cells treated with ITO NPs for $24 \mathrm{~h}$.

\section{Supporting Figure S8.}

Fluorescence images (left), bright field images (middle), and overlays of the fluorescence and bright field images (right), with the z-positions analysed through the $9^{\text {th }}, 10^{\text {th }}, 11^{\text {th }}$, and $13^{\text {th }}$ sections of MCF-10A cells treated with ITO NPs for $24 \mathrm{~h}$.

\section{Supporting Figure S9.}

ITO NPs mediated production or scavenging of the intracellular ROS in MDA-MB-231, MCF-7, and MCF-10A cells. [(A) and (B), Flow cytometric results of ITO NP induced generation of intracellular ROS in breast cancer MDA-MB-231 and MCF-7 cells, respectively. (C) Flow cytometric results of ITO mediated prevention of intracellular ROS in normal MCF-10A breast cells.] The above description with marked in red has been deleted.

\section{Supporting Figure S10.}

Scattergrams of 7-AAD stained cells with gating are shown.

\section{Supporting Figure S11.}

Quantitative clonogenic results for 9L (left) and MDCK cells (right) treated with and without the engineered ITO NPs.

\section{References}

(1) Circu, M. L.; Aw, T. Y. Reactive Oxygen Species, Cellular Redox Systems, and Apoptosis. Free Radical Biol. Med. 2010, 48 (6), 749-762.

(2) Simon, H. U.; Haj-Yehia, A.; Levi-Schaffer, F. Role of Reactive Oxygen Species (ROS) in Apoptosis Induction. Apoptosis 2000, 5 (5), 415-418.

(3) Zhang, Z.; He, X.; Zhou, C.; Reaume, M.; Wu, M.; Liu, B.; Lee, B. P. Iron Magnetic NanoparticleInduced ROS Generation from Catechol-Containing Microgel for Environmental and Biomedical Applications. ACS Appl. Mater. Interfaces 2020, 12 (19), 21210-21220

(4) Rzigalinski, B. A. Nanoparticles and Cell Longevity. Technol. Cancer Res. Treat. 2005, 4 (6), 651-659.

(5) Barnham, K. J.; Masters, C. L.; Bush, A. I. Neurodegenerative Diseases and Oxidative Stress. Nat. Rev. Drug Discovery 2004, 3 (3), 205-214. 
(6) Dandona, P.; Aljada, A.; Bandyopadhyay, A. Inflammation: The Link between Insulin Resistance, Obesity and Diabetes. Trends in Immunology 2004, 25 (1), 4-7.

(7) Reuter, S.; Gupta, S. C.; Chaturvedi, M. M.; Aggarwal, B. B. Oxidative Stress, Inflammation, and Cancer: How Are They Linked? Free Radical Biol. Med. 2010, 49 (11), 1603-1616.

(8) Chen, S.-R.; Li, Y.; Wu, B.-Y.; Xu, H. A New Heterometallic Mof in Cyanosilylation Reaction, Treatment and Care Management Value in Stroke by Reducing Oxidative Stress Damage. Bull. Chem. Soc. Jpn. 2020, 93 (1), 43-49.

(9) Liu, J.; Li, Y.; Chen, S.; Lin, Y.; Lai, H.; Chen, B.; Chen, T. Biomedical Application of Reactive Oxygen Species-Responsive Nanocarriers in Cancer, Inflammation, and Neurodegenerative Diseases. Front. Chem. 2020, 8 (838).

(10) Zhou, Z.; Ni, K.; Deng, H.; Chen, X. Dancing with Reactive Oxygen Species Generation and Elimination in Nanotheranostics for Disease Treatment. Adv. Drug Delivery Rev. 2020.

(11) Martinon, F. Signaling by ROS Drives Inflammasome Activation. European Journal of Immunology 2010, 40 (3), 616-619.

(12) Droge, W. Free Radicals in the Physiological Control of Cell Function. Physiol. Rev. 2002, 82 (1), $47-$ 95.

(13) Holbrook, N. J.; Ikeyama, S. Age-Related Decline in Cellular Response to Oxidative Stress: Links to Growth Factor Signaling Pathways with Common Defects. Biochem. Pharmacol. 2002, 64 (5-6), 999-1005.

(14) Klein, S.; Sommer, A.; Distel, L. V.; Hazemann, J.-L.; Kröner, W.; Neuhuber, W.; Müller, P.; Proux, O.; Kryschi, C. Superparamagnetic Iron Oxide Nanoparticles as Novel X-Ray Enhancer for Low-Dose Radiation Therapy. The Journal of Physical Chemistry B 2014, 118 (23), 6159-6166.

(15) Wang, Y.; Zi, X.-Y.; Su, J.; Zhang, H.-X.; Zhang, X.-R.; Zhu, H.-Y.; Li, J.-X.; Yin, M.; Yang, F.; Hu, Y.-P. Cuprous Oxide Nanoparticles Selectively Induce Apoptosis of Tumor Cells. Int. J. Nanomed. 2012, 7 , 2641 . 
(16) Wang, Y.; Yang, F.; Zhang, H.; Zi, X.; Pan, X.; Chen, F.; Luo, W.; Li, J.; Zhu, H.; Hu, Y. Cuprous Oxide Nanoparticles Inhibit the Growth and Metastasis of Melanoma by Targeting Mitochondria. Cell Death \& Disease 2013, 4 (8), e783-e783.

(17) Ostrovsky, S.; Kazimirsky, G.; Gedanken, A.; Brodie, C. Selective Cytotoxic Effect of ZnO Nanoparticles on Glioma Cells. Nano Res. 2009, 2 (11), 882-890.

(18) Akhtar, M. J.; Ahamed, M.; Kumar, S.; Khan, M. M.; Ahmad, J.; Alrokayan, S. A. Zinc Oxide Nanoparticles Selectively Induce Apoptosis in Human Cancer Cells through Reactive Oxygen Species. Int. J. Nanomed. 2012, 7, 845 .

(19) Chattopadhyay, S.; Dash, S. K.; Tripathy, S.; Pramanik, P.; Roy, S. Phosphonomethyl Iminodiacetic Acid-Conjugated Cobalt Oxide Nanoparticles Liberate $\mathrm{Co}^{++}$Ion-Induced Stress Associated Activation of TNF- $\alpha /$ P38 MAPK/Caspase 8-Caspase 3 Signaling in Human Leukemia Cells. JBIC Journal of Biological Inorganic Chemistry 2015, 20 (1), 123-141.

(20) Iqbal, J.; Abbasi, B. A.; Ahmad, R.; Mahmoodi, M.; Munir, A.; Zahra, S. A.; Shahbaz, A.; Shaukat, M.; Kanwal, S.; Uddin, S. Phytogenic Synthesis of Nickel Oxide Nanoparticles (NiO) Using Fresh Leaves Extract of Rhamnus triquetra (Wall.) and Investigation of Its Multiple in Vitro Biological Potentials. Biomedicines 2020, 8 (5), 117.

(21) Narayanan, K. B.; Park, H. H. Pleiotropic Functions of Antioxidant Nanoparticles for Longevity and Medicine. Adv. Colloid Interface Sci. 2013, 201, 30-42.

(22) Madvar, A.; Rezaee, F.; Jalali, V. Effects of Alumina Nanoparticles on Morphological Properties and Antioxidant System of Triticum aestivum. Iranian Journal of Plant Physiology 2012, 3, 595-603.

(23) Chen, Z.; Yin, J.-J.; Zhou, Y.-T.; Zhang, Y.; Song, L.; Song, M.; Hu, S.; Gu, N. Dual Enzyme-Like Activities of Iron Oxide Nanoparticles and Their Implication for Diminishing Cytotoxicity. ACS Nano 2012, $6(5), 4001-4012$.

(24) Yao, J.; Cheng, Y.; Zhou, M.; Zhao, S.; Lin, S.; Wang, X.; Wu, J.; Li, S.; Wei, H. ROS Scavenging $\mathrm{Mn}_{3} \mathrm{O}_{4}$ Nanozymes for in Vivo Anti-Inflammation. Chem. Sci. 2018, 9 (11), 2927-2933. 
(25) Schubert, D.; Dargusch, R.; Raitano, J.; Chan, S.-W. Cerium and Yttrium Oxide Nanoparticles Are Neuroprotective. Biochem. Biophys. Res. Commun. 2006, 342 (1), 86-91.

(26) Wason, M. S.; Colon, J.; Das, S.; Seal, S.; Turkson, J.; Zhao, J.; Baker, C. H. Sensitization of Pancreatic Cancer Cells to Radiation by Cerium Oxide Nanoparticle-Induced ROS Production. Nanomed. Nanotechnol. Biol. Med. 2013, 9 (4), 558-569.

(27) Tarnuzzer, R. W.; Colon, J.; Patil, S.; Seal, S. Vacancy Engineered Ceria Nanostructures for Protection from Radiation-Induced Cellular Damage. Nano Lett. 2005, 5 (12), 2573-2577.

(28) Colon, J.; Hsieh, N.; Ferguson, A.; Kupelian, P.; Seal, S.; Jenkins, D. W.; Baker, C. H. Cerium Oxide Nanoparticles Protect Gastrointestinal Epithelium from Radiation-Induced Damage by Reduction of Reactive Oxygen Species and Upregulation of Superoxide Dismutase 2. Nanomed. Nanotechnol. Biol. Med. 2010, 6 (5), 698-705.

(29) Alili, L.; Sack, M.; Karakoti, A. S.; Teuber, S.; Puschmann, K.; Hirst, S. M.; Reilly, C. M.; Zanger, K.; Stahl, W.; Das, S. Combined Cytotoxic and Anti-Invasive Properties of Redox-Active Nanoparticles in Tumor-Stroma Interactions. Biomaterials 2011, 32 (11), 2918-2929.

(30) Sack, M.; Alili, L.; Karaman, E.; Das, S.; Gupta, A.; Seal, S.; Brenneisen, P. Combination of Conventional Chemotherapeutics with Redox-Active Cerium Oxide Nanoparticles-A Novel Aspect in Cancer Therapy. Molecular Cancer Therapeutics 2014, 13 (7), 1740-1749.

(31) Alili, L.; Sack, M.; Montfort, C.; Giri, S.; Das, S.; Carroll, K. S.; Zanger, K.; Seal, S.; Brenneisen, P. Downregulation of Tumor Growth and Invasion by Redox-Active Nanoparticles. Antioxid. Redox Signaling. 2013, $19(8), 765-778$.

(32) Pešić, M.; Podolski-Renić, A.; Stojković, S.; Matović, B.; Zmejkoski, D.; Kojić, V.; Bogdanović, G.; Pavićević, A.; Mojović, M.; Savić, A. Anti-Cancer Effects of Cerium Oxide Nanoparticles and Its Intracellular Redox Activity. Chem. Biol. Interact. 2015, 232, 85-93.

(33) Sharma, H.; Mishra, P. K.; Talegaonkar, S.; Vaidya, B. Metal Nanoparticles: A Theranostic Nanotool against Cancer. Drug Discovery Today 2015, 20 (9), 1143-1151. 
(34) Janib, S. M.; Moses, A. S.; MacKay, J. A. Imaging and Drug Delivery Using Theranostic Nanoparticles. Adv. Drug Delivery Rev. 2010, 62 (11), 1052-1063.

(35) Muthu, M. S.; Leong, D. T.; Mei, L.; Feng, S. S. Nanotheranostics- Application and Further Development of Nanomedicine Strategies for Advanced Theranostics. Theranostics 2014, 4 (6), 660.

(36) Wang, Y.; Song, S.; Liu, J.; Liu, D.; Zhang, H. ZnO-Functionalized Upconverting Nanotheranostic Agent: Multi-Modality Imaging-Guided Chemotherapy with On-Demand Drug Release Triggered by $\mathrm{pH}$. Angew. Chem. Int. Ed. 2015, 54 (2), 536-540.

(37) Ni, D.; Bu, W.; Zhang, S.; Zheng, X.; Li, M.; Xing, H.; Xiao, Q.; Liu, Y.; Hua, Y.; Zhou, L. Single $\mathrm{Ho}^{3+}$-Doped Upconversion Nanoparticles for High-Performance $\mathrm{T}_{2}$-Weighted Brain Tumor Diagnosis and MR/UCL/CT Multimodal Imaging. Adv. Funct. Mater. 2014, 24 (42), 6613-6620.

(38) Liu, Z.; Pu, F.; Huang, S.; Yuan, Q.; Ren, J.; Qu, X. Long-Circulating $\mathrm{Gd}_{2} \mathrm{O}_{3}$ : $\mathrm{Yb}^{3+}$, $\mathrm{Er}^{3+} \mathrm{Up}^{-C o n v e r s i o n}$ Nanoprobes as High-Performance Contrast Agents for Multi-Modality Imaging. Biomaterials 2013, 34 (6), 1712-1721.

(39) Li, S.; Tian, M.; Gao, Q.; Wang, M.; Li, T.; Hu, Q.; Li, X.; Wu, Y. Nanometre-Thin Indium Tin Oxide for Advanced High-Performance Electronics. Nat. Mater. 2019, 1-7.

(40) Horiuchi, N. Light-Emitting Indium Tin Oxide. Nat. Photonics 2011, 5 (6), 332-332.

(41) Bruchez, M.; Moronne, M.; Gin, P.; Weiss, S.; Alivisatos, A. P. Semiconductor Nanocrystals as Fluorescent Biological Labels. Science 1998, 281 (5385), 2013-2016.

(42) Smith, A. M.; Duan, H.; Mohs, A. M.; Nie, S. Bioconjugated Quantum Dots for in Vivo Molecular and Cellular Imaging. Adv. Drug Delivery Rev. 2008, 60 (11), 1226-1240.

(43) Murdock, R. C.; Braydich-Stolle, L.; Schrand, A. M.; Schlager, J. J.; Hussain, S. M. Characterization of Nanomaterial Dispersion in Solution Prior to in Vitro Exposure Using Dynamic Light Scattering Technique. Toxicol. Sci. 2008, 101 (2), 239-253.

(44) Fan, J. C.; Goodenough, J. B. X-Ray Photoemission Spectroscopy Studies of Sn-Doped Indium-Oxide Films. J. Appl. Phys. 1977, 48 (8), 3524-3531. 
(45) Peng, X.; Meng, G.; Wang, X.; Wang, Y.; Zhang, J.; Liu, X.; Zhang, L. Synthesis of Oxygen-Deficient Indium-Tin-Oxide (ITO) Nanofibers. Chem. Mater. 2002, 14 (11), 4490-4493.

(46) Kim, J.; Ho, P.; Thomas, D.; Friend, R.; Cacialli, F.; Bao, G.-W.; Li, S. X-Ray Photoelectron Spectroscopy of Surface-Treated Indium-Tin Oxide Thin Films. Chem. Phys. Lett. 1999, 315 (5-6), 307-312.

(47) Donley, C.; Dunphy, D.; Paine, D.; Carter, C.; Nebesny, K.; Lee, P.; Alloway, D.; Armstrong, N. R. Characterization of Indium-Tin Oxide Interfaces Using X-Ray Photoelectron Spectroscopy and Redox Processes of a Chemisorbed Probe Molecule: Effect of Surface Pretreatment Conditions. Langmuir 2002, 18 (2), 450-457.

(48) Chang, W.-C.; Kuo, C.-H.; Lee, P.-J.; Chueh, Y.-L.; Lin, S.-J. Synthesis of Single Crystal Sn-Doped $\mathrm{In}_{2} \mathrm{O}_{3}$ Nanowires: Size-Dependent Conductive Characteristics. Physical Chemistry Chemical Physics 2012, 14 (37), 13041-13045.

(49) Hartnagel, H. Semiconducting Transparent Thin Films, 1995, Institute of Physics Bristol

(50) Yumoto, H.; Sako, T.; Gotoh, Y.; Nishiyama, K.; Kaneko, T. Growth Mechanism of Vapor-Liquid-Solid (VLS) Grown Indium Tin Oxide (ITO) Whiskers Along the Substrate. J. Cryst. Growth 1999, 203 (1-2), 136140.

(51) Frank, G.; Brock, L.; Bausen, H. The Solubilities of $\mathrm{Sn}$ in $\mathrm{In}_{2} \mathrm{O}_{3}$ and of In in $\mathrm{SnO}_{2}$ Crystals Grown from Sn-In Melts. J. Cryst. Growth. 1976, 36 (1), 179-180.

(52) Crist, B. V. Handbook of the Elements and Native Oxides, XPS International. 1999, California (53) Qin, K.; Mei, F.; Yuan, T.; Li, R.; Jiang, J.; Niu, P.; Chen, H. Effects of Sintering Processes on the Element Chemical States of In, Sn and O in ITO Targets. Journal of Materials Science: Materials in Electronics 2018, 29 (10), 7931-7940.

(54) Suzuki, H.; Toyooka, T.; Ibuki, Y. Simple and Easy Method to Evaluate Uptake Potential of Nanoparticles in Mammalian Cells Using a Flow Cytometric Light Scatter Analysis. Environ. Sci. Technol. 2007, 41 (8), 3018-3024. 
(55) Alwani, S.; Kaur, R.; Michel, D.; Chitanda, J. M.; Verrall, R. E.; Karunakaran, C.; Badea, I. LysineFunctionalized Nanodiamonds as Gene Carriers: Development of Stable Colloidal Dispersion for in Vitro Cellular Uptake Studies and siRNA Delivery Application. Int. J. Nanomed. 2016, 11, 687.

(56) Lu, Y.; Li, L.; Lin, Z.; Li, M.; Hu, X.; Zhang, Y.; Peng, M.; Xia, H.; Han, G. Enhancing Osteosarcoma Killing and CT Imaging Using Ultrahigh Drug Loading and NIR-Responsive Bismuth Sulfide@ Mesoporous Silica Nanoparticles. Adv. Healthcare Mater. 2018, 7 (19), 1800602.

(57) Dong, L.; Zhang, P.; Xu, X.; Lei, P.; Du, K.; Zhang, M.; Wang, D.; Feng, J.; Li, W.; Zhang, H. Simple Construction of $\mathrm{Cu}_{2} \mathrm{xS}$ : Pt Nanoparticles as Nanotheranostic Agent for Imaging-Guided ChemoPhotothermal Synergistic Therapy of Cancer. Nanoscale 2018, 10 (23), 10945-10951.

(58) Wang, H.; Joseph, J. A. Quantifying Cellular Oxidative Stress by Dichlorofluorescein Assay Using Microplate Reader. Free Radical Biol. Med. 1999, 27 (5-6), 612-616.

(59) Núñez, C.; Estévez, S. V.; del Pilar Chantada, M. Inorganic Nanoparticles in Diagnosis and Treatment of Breast Cancer. JBIC Journal of Biological Inorganic Chemistry 2018, 23 (3), 331-345.

(60) Bogusz, K.; Tehei, M.; Cardillo, D.; Lerch, M.; Rosenfeld, A.; Dou, S. X.; Liu, H.-K.; Konstantinov, K. High Toxicity of $\mathrm{Bi}(\mathrm{OH})_{3}$ and $\alpha-\mathrm{Bi}_{2} \mathrm{O}_{3}$ Nanoparticles Towards Malignant 9L and MCF-7 Cells. Materials Science and Engineering: C 2018, 93, 958-967.

(61) Tabei, Y.; Sonoda, A.; Nakajima, Y.; Biju, V.; Makita, Y.; Yoshida, Y.; Horie, M. In Vitro Evaluation of the Cellular Effect of Indium Tin Oxide Nanoparticles Using the Human Lung Adenocarcinoma A549 Cells. Metallomics 2015, 7 (5), 816-827.

(62) Xu, C.; Qu, X. Cerium Oxide Nanoparticle: A Remarkably Versatile Rare Earth Nanomaterial for Biological Applications. NPG Asia Mater. 2014, 6 (3), e90-e90.

(63) Korsvik, C.; Patil, S.; Seal, S.; Self, W. T. Superoxide Dismutase Mimetic Properties Exhibited by Vacancy Engineered Ceria Nanoparticles. Chem. Commun. 2007, (10), 1056-1058.

(64) Rzigalinski, B. A.; Carfagna, C. S.; Ehrich, M. Cerium Oxide Nanoparticles in Neuroprotection and Considerations for Efficacy and Safety. Wiley Interdiscip. Rev. Nanomed. Nanobiotechnol. 2017, 9 (4), e1444. 
(65) Lin, W.; Huang, Y.-w.; Zhou, X.-D.; Ma, Y. Toxicity of Cerium Oxide Nanoparticles in Human Lung Cancer Cells. Int. J. Toxicol. 2006, 25 (6), 451-457.

(66) Zhu, J.; Zhang, G.; Xian, G.; Zhang, N.; Li, J. A High-Efficiency CuO/CeO 2 Catalyst for Diclofenac Degradation in Fenton-Like System. Front. Chem. 2019, 7.

(67) Celardo, I.; Pedersen, J. Z.; Traversa, E.; Ghibelli, L. Pharmacological Potential of Cerium Oxide Nanoparticles. Nanoscale 2011, 3 (4), 1411-1420.

(68) Zembruski, N. C.; Stache, V.; Haefeli, W. E.; Weiss, J. 7-Aminoactinomycin D for Apoptosis Staining in Flow Cytometry. Anal. Biochem. 2012, 429 (1), 79-81.

(69) Koopman, G.; Reutelingsperger, C.; Kuijten, G.; Keehnen, R.; Pals, S.; Van Oers, M. Annexin V for Flow Cytometric Detection of Phosphatidylserine Expression on B Cells Undergoing Apoptosis. Blood 1994, $84,1415-1420$.

(70) Franken, N. A.; Rodermond, H. M.; Stap, J.; Haveman, J.; Van Bree, C. Clonogenic Assay of Cells in Vitro. Nat. Protoc. 2006, 1 (5), 2315-2319.

\section{Supporting Information}

Implementation of Oxide Nano-particles in Medicine as Oxi-redox Theranostic Systems Based on Controlled Generation or Prevention of Oxidative Stress: An In-vitro Study of In-based Oxide Nanoparticles for Selective Breast Cancer Treatment 
Nai-Sheng HSU ${ }^{a, b}$, Moeava Tehei ${ }^{b, d}$, Md Shahriar Hossain ${ }^{e}$, Anatoly Rosenfeld ${ }^{b, d}$, Muhammad J. A. Shiddiky ${ }^{f}$ Ronald Slyuter ${ }^{b, c}$, Shi Xue Dou ${ }^{a}$, Yusuke Yamauchi ${ }^{* * g}$ and Konstantin Konstantinov*a,b

${ }^{a}$ Institute for Superconducting and Electronic Materials, Australian Institute for Innovative Materials, University of Wollongong, 2500 North Wollongong, NSW, Australia.

${ }^{b}$ Illawarra Health and Medical Research Institute, University of Wollongong, 2500 Wollongong, NSW, Australia.

${ }^{c}$ School of Chemistry and Medical Biology, Faculty of Science, Medicine and Health, University of Wollongong, 2500 Wollongong, NSW, Australia.

${ }^{d}$ Centre for Medical and Radiation Physics, Faculty of Engineering and Information Science, University of Wollongong, 2500 Wollongong, NSW, Australia.

${ }^{e}$ Australian Institute for Bioengineering and Nanotechnology, School of Mechanical and Mining Engineering, Faculty of Engineering, Architecture and Information Technology, The University of Queensland, 4072 Brisbane, QLD, Australia

${ }^{f}$ School of Environment and Science (ESC) \& Queensland Micro- and Nanotechnology Centre (QMNC), Griffith University, Nathan campus, Nathan, QLD 4111, Australia

$g$ Australian Institute for Bioengineering and Nanotechnology, School of Chemical Engineering, The University of Queensland, 4702 Brisbane, QLD, Australia

Corresponding authors: konstan@uow.edu.au; y.yamauchi@uq.edu.au 


\section{Supporting Table}

\begin{tabular}{|c|c|c|}
\hline \multicolumn{2}{|r|}{$(w t \%)$} & Indium : Tin \\
\hline \multicolumn{2}{|r|}{ ITOH (ITO Precursors) } & $90.01 \% \operatorname{In}(\mathrm{OH})_{3}$ \\
\hline \multicolumn{3}{|c|}{ : $9.99 \% \mathrm{Sn}(\mathrm{OH})_{2}$} \\
\hline \multicolumn{2}{|c|}{ ITO $\quad\left(400^{\circ} \mathrm{C}\right.$ Annealed $)$} & $89.72 \% \mathrm{In}_{2} \mathrm{O}_{3}$ : \\
\hline & $10.28 \% \mathrm{SnO}_{2}$ & \\
\hline
\end{tabular}

Abbreviations: ITO: Indium Tin Oxide; ITOH: Indium Tin Hydroxide.

Supporting Table S1. EDS results for ITOH (ITO precursors) and ITO nanoparticles. 


\section{Supporting Figures}

A

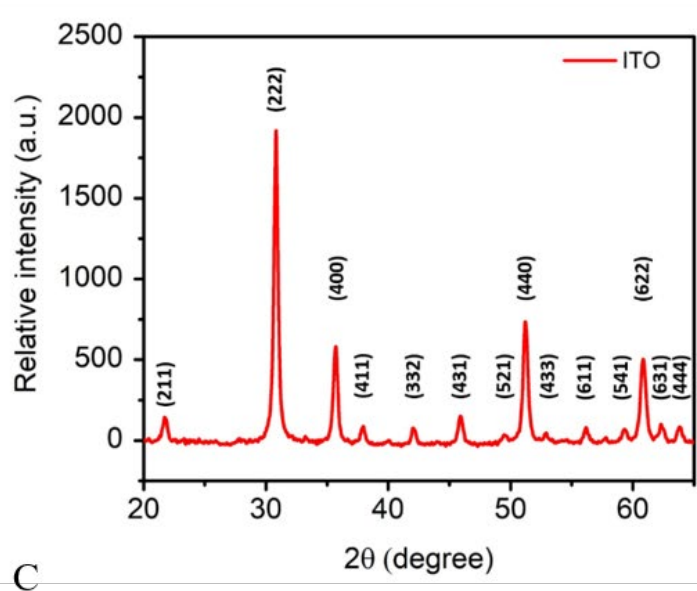

B

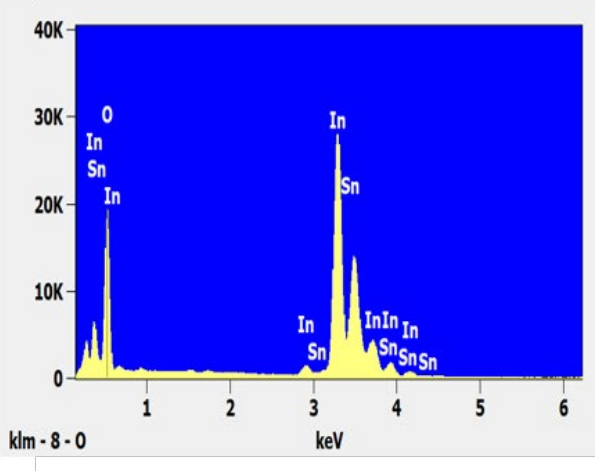

$\mathrm{D}$

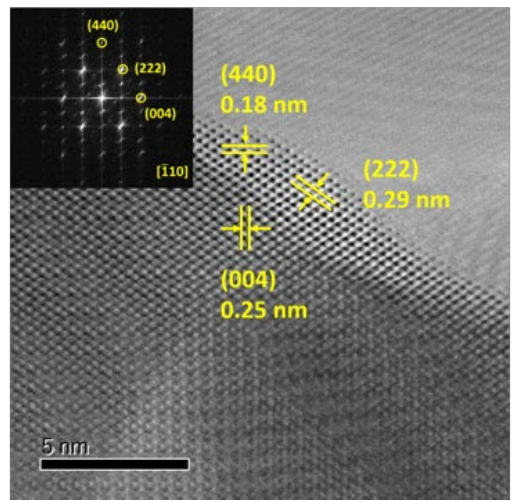

\section{Supporting Figure S1.}

(A) X-ray diffraction pattern, (B) EDS spectrum, (C) TEM image, and (D) HR-TEM image with an inset of corresponding FFT pattern of the synthesized ITO NPs.

Note for Supporting Figure S1: The X-ray powder diffraction pattern of the obtained ITO NPs is shown in Figure 1A. The corresponding peaks in Figure 1A demonstrate that the synthesized nanomaterials are a single phase of $\operatorname{In}_{2} \mathrm{O}_{3}$ powders with body-centred cubic crystalline structure, in which no significant peaks corresponding to $\mathrm{SnO}, \mathrm{SnO}_{2}$ or other impurities were detected, and the ITO lattice parameter remained unchanged, according to the Joint Committee on Powder Diffraction Standards file (JCPDS \# 06-0416). The results suggest that the $\mathrm{Sn}$ atoms were well incorporated into the $\mathrm{In}_{2} \mathrm{O}_{3}$ crystal lattice. Figure $1 \mathrm{~B}$ represents the results of the energy dispersive X-ray spectroscopy (EDS) analysis, showing that no other elemental impurity was present in the prepared ITO crystal structure. The characteristics of the 
final powders with an expected weight ratio of approximately 9:1 of $\operatorname{In}_{2} \mathrm{O}_{3}$ to $\mathrm{SnO}_{2}$ are displayed in Supplementary Table S1. The average crystallite size $(d)$ of the prepared ITO NPs can be calculated by the Scherrer equation, based on the XRD pattern. The calculated average crystallite size of the synthesized ITO NPs was found to be $10.78 \pm 1.42 \mathrm{~nm}$. Figure 1(C-D) shows transmission electron microscope (TEM) and high-resolution TEM (HRTEM) image with the fast Fourier transform (FFT) pattern of the ITO NPs. As can be seen from Figure 1C, the synthesized ITO NPs mainly formed aggregates greater than $50 \mathrm{~nm}$ in size. The HRTEM image displayed in Figure 1D reveals the ITO nanostructure with lattice spacing of 0.29, 0.25, and $0.18 \mathrm{~nm}$, which are in accordance with the $d$-spacing of the (222), (004), and (440) planes, respectively. The results are in agreement with our XRD spectrum (Figure. 1A). The inset of FFT pattern in Figure 1D presents the major lattice planes, which also confirms the crystallinity of the ITO NPs. 


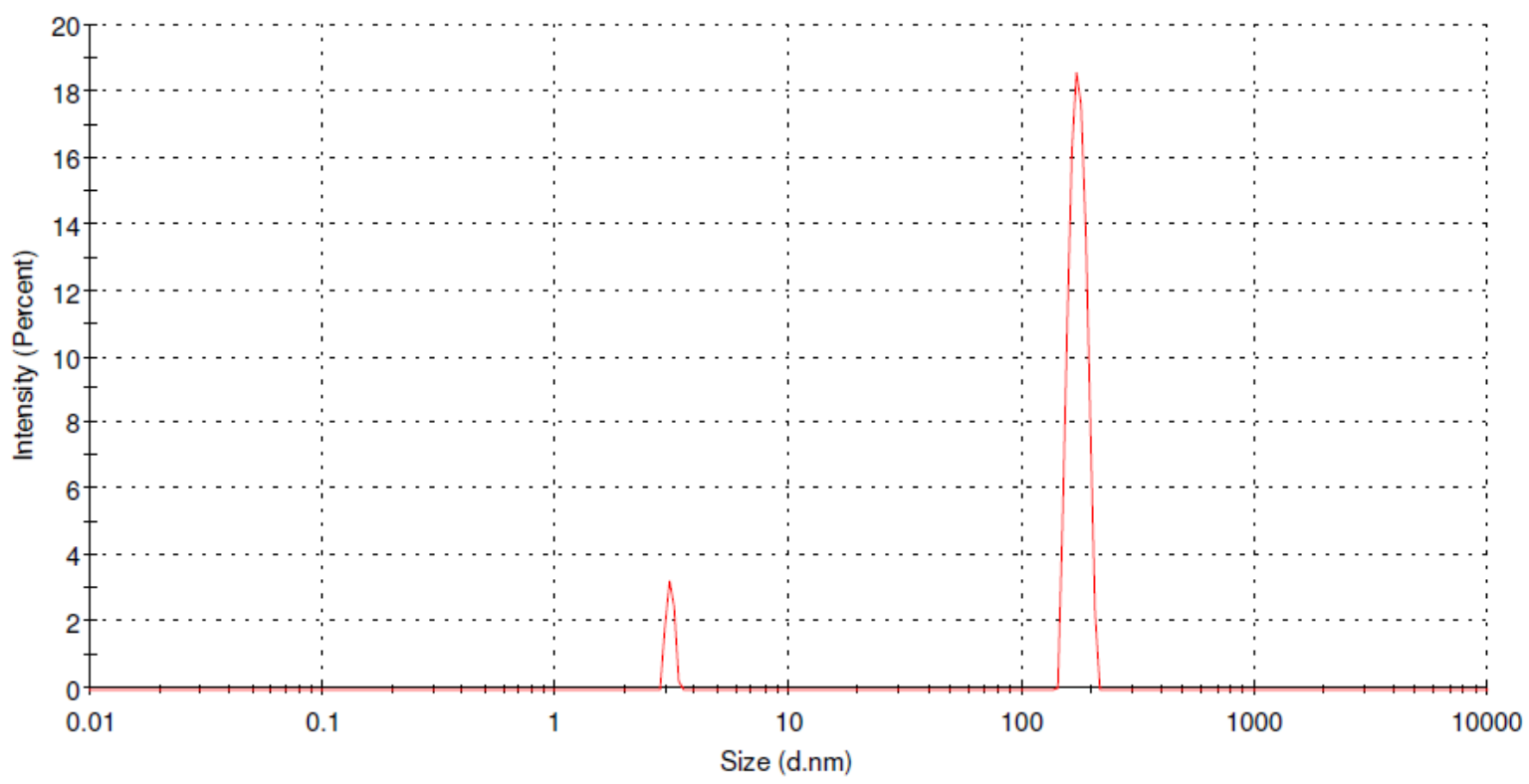

Supporting Figure S2.

Hydrodynamic diameter of ITO NPs suspended in PBS, determined via dynamic light scattering.

The concentration of the suspension of ITO NPs is $50 \mu \mathrm{g} / \mathrm{mL}$. 

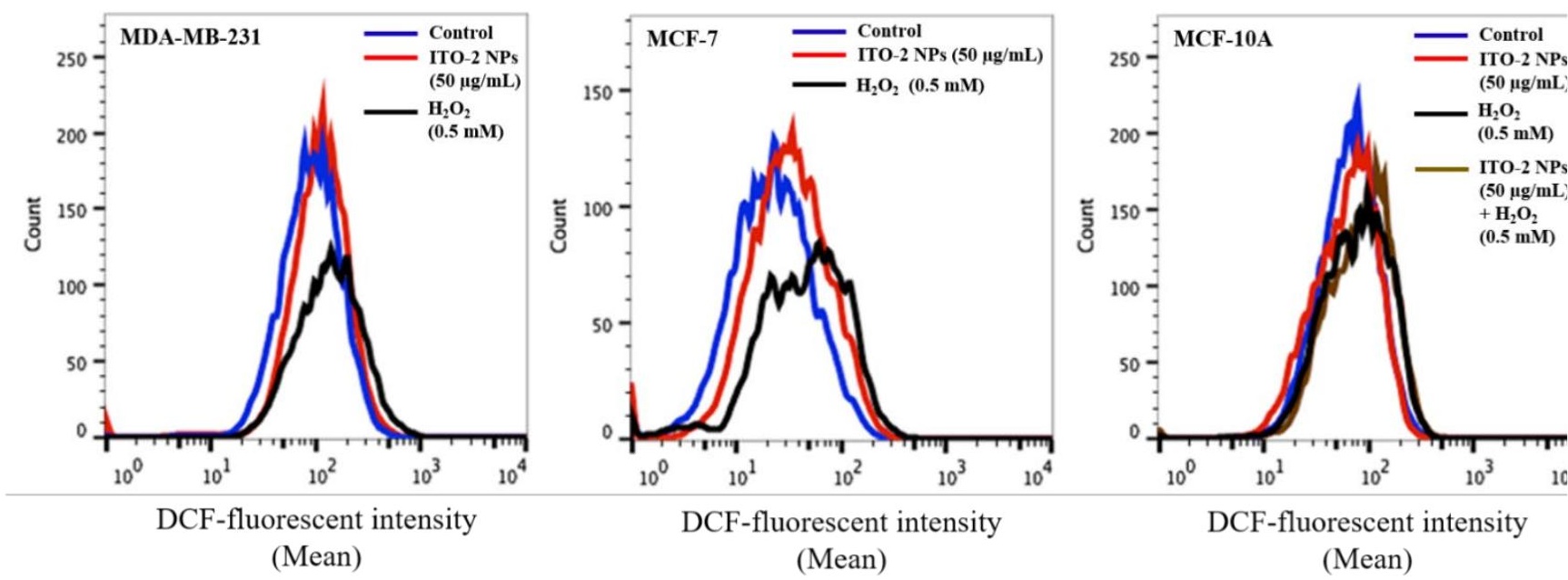

\section{Supporting Figure S3.}

ITO-2 NPs induced generation of the intracellular ROS in MDA-MB-231 (left), MCF-7 (meddle), and MCF-10A cells (right). The different colours represent different treatments, and the change in the DCF-fluorescent intensity represents the change in the intracellular ROS level in MDA-MB-231, MCF-7, and MCF-10A cells, respectively. Control represents the cells without any treatment. Cells treated with ITO-2 NPs in a concentration of $50 \mu \mathrm{g} / \mathrm{mL}$ induced significant production of ROS in both cancerous MDA-MB-231(left panel) and MCF-7 (middle panel). No noticeable ROS change was detected in MCF-10A cells after treatment of ITO-2 NPs $(50 \mu \mathrm{g} / \mathrm{mL})$, and no ROS prevention was observed after MCF-10A cells were treated with ITO-2 NPs $(50 \mu \mathrm{g} / \mathrm{mL})$ and $\mathrm{H}_{2} \mathrm{O}_{2}(0.5 \mathrm{mM})$ (right panel). 


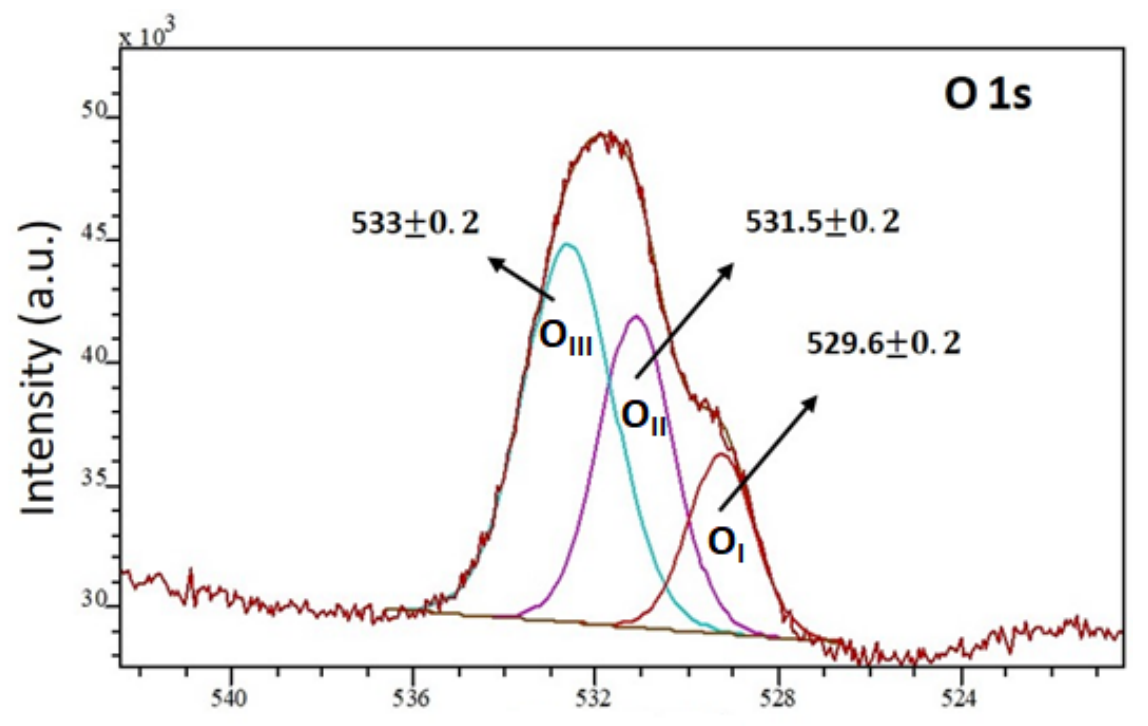

\section{Supporting Figure S4.}

High-resolution XPS O 1s spectrum for ITO-2 NPs. ITO-2 NPs are the material synthesized under the same conditions as ITO-1 but annealed in air. 

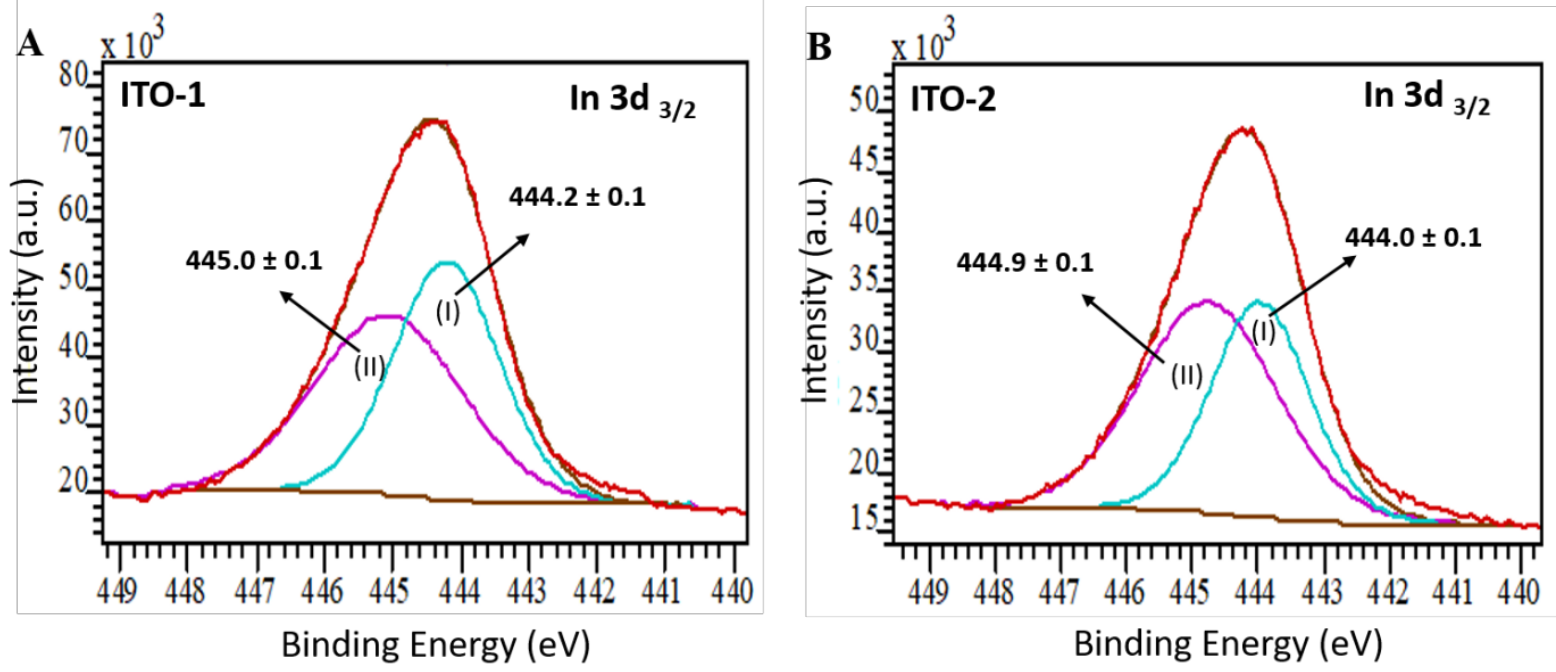

\section{Supporting Figure S5.}

High-resolution XPS spectra of (A) In $3 \mathrm{~d}_{3 / 2}$ of ITO-1 NPs, (B) In $3 \mathrm{~d}_{3 / 2}$ of ITO-2 NPs.

Note for Supporting Figure S5: ITO-1 NPs are the material that we studied in this article, and ITO-2 NPs are the material that was synthesized under the same conditions as ITO-1 but annealed in air. In both spectra, the In $3 \mathrm{~d}_{3 / 2}$ peak was deconvoluted by a Gaussian function into two components of In $3 \mathrm{~d}_{3 / 2}$ (I), and In $3 \mathrm{~d}_{3 / 2}$ (II) at the binding energies of approximately 444 and $445 \mathrm{eV}$, respectively. The In $3 \mathrm{~d}_{3 / 2}$ peak located at the lower binding energy of $\sim 444 \mathrm{eV}$ $\left(\operatorname{In} 3 \mathrm{~d}_{3 / 2}(\mathrm{I})\right)$ corresponds to the $\mathrm{In}^{2+}$ bonding state originating from a response associated with the loss of oxygen: the $\operatorname{In}_{2} \mathrm{O}_{3-x}$ state, and the peak located at the higher binding energy of $\sim 445$ $\mathrm{eV}$ (In $3 \mathrm{~d}_{3 / 2}$ (II)) corresponds to the $\mathrm{In}^{3+}$ bonding state from $\operatorname{In}_{2} \mathrm{O}_{3} .{ }^{51,52}$ The calculated ratios of the areas of the In $3 \mathrm{~d}_{3 / 2}$ peaks $\left(\operatorname{In}_{3} \mathrm{~d}_{3 / 2}\right.$ (I)/In $3 \mathrm{~d}_{3 / 2}$ (II)) in ITO- 1 and ITO-2 were 0.95 and 0.72 , respectively. The increase for the In $3 \mathrm{~d}_{3 / 2}$ (I) state in ITO-1 was due to an increase in $\mathrm{In}^{2+}, 52$ suggesting that more $\mathrm{In}^{3+}$ was converted into In-O bonds in the ITO-1 NPs due to annealing in a reducing atmosphere. 
A

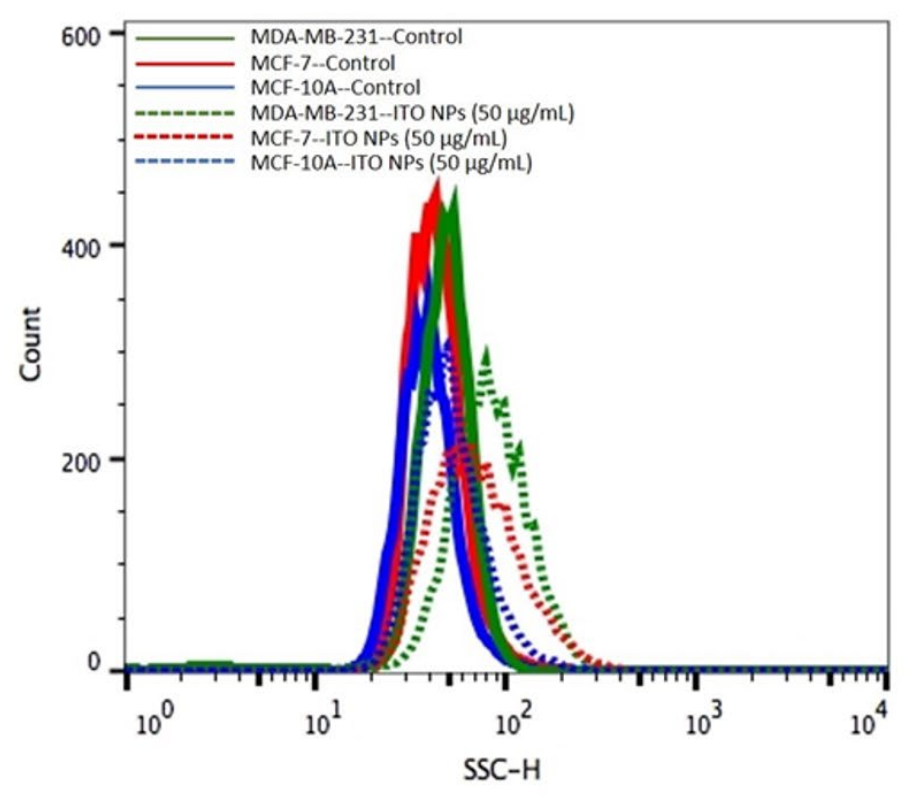

B

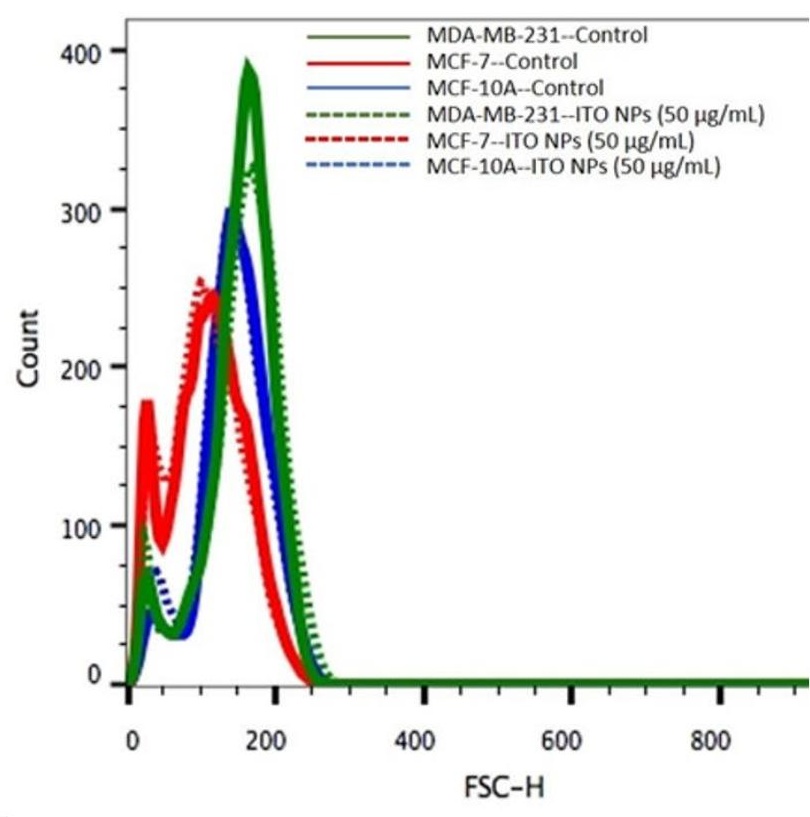

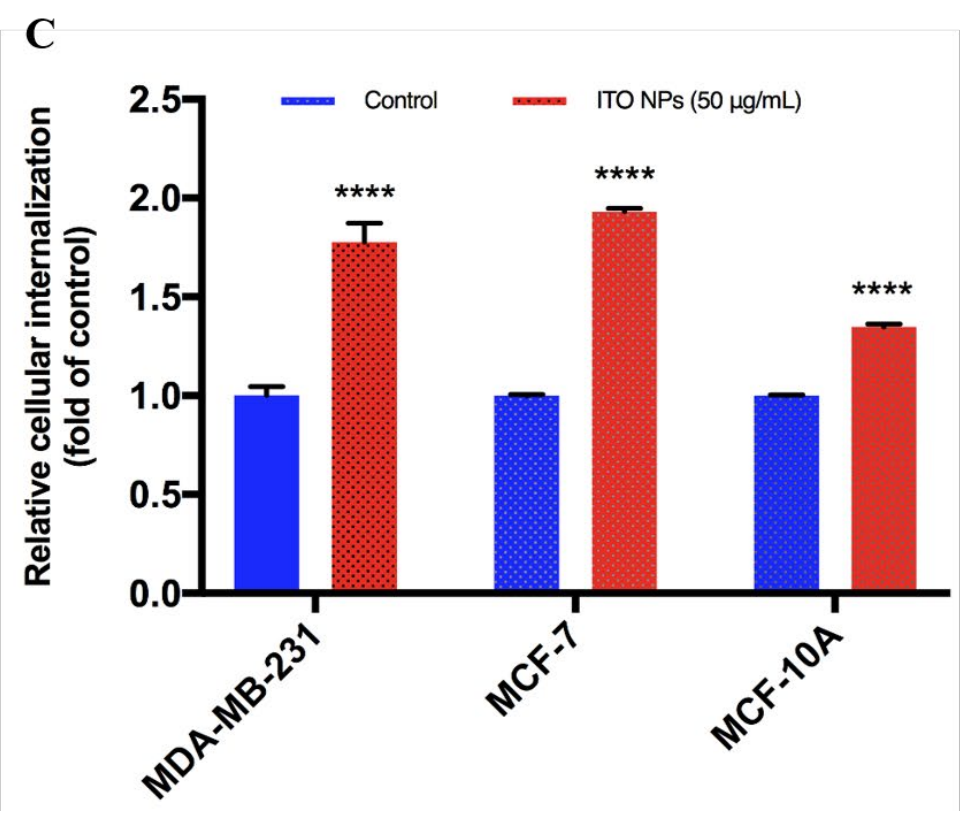

\section{Supporting Figure S6.}

Flow cytometry histograms (A) and (B) show the cellular internalization of ITO NPs through side and forward scattering, respectively, in MDA-MB-231, MCF-7, and MCF-10A cells. Comparisons of cellular internalization between different control and treated samples were quantified and are presented as (C). In (A) and (B), the control and treated samples were the cells without ITO NP exposure and the cells with treatment by ITO NPs at a concentration of $50 \mu \mathrm{g} / \mathrm{mL}$ for 24 hours, respectively. The straight lines and dotted lines represent the control 
samples and treated samples, respectively. The different colours, green, red, and blue, represent the MDA-MB-231, MCF-7, and MCF-10A cell lines, respectively. In (C), the control and the treated samples in different cells are represented by blue bars, and red bars, respectively. The **** indicates $p<0.0001$ for the comparison with the corresponding control sample.

Note for Supporting Figure S6: In Figure S6A, untreated cells exhibited the least SSC, but after treatment with ITO NPs, the cells exhibited a significant increase in SSC, indicating the uptake of ITO NPs. While there was a change in the SSC, the FSC of cells remained unchanged by treatment with ITO NPs compared to the untreated cells (Figure S6B). This suggested that the ITO NPs were internalized into the cells and did not adhere to the surfaces of the cells. ${ }^{53,54}$ The quantitative results in Figure S6C show that the ITO nanoparticles were internalized by the MDA-MB-231, MCF-7, and MCF-10A cells by factors of around 1.77, 1.93, and 1.35 fold over the corresponding untreated samples, respectively. The results indicated a difference in cellular uptake of ITO NPs between malignant and non-malignant human breast cells, and such different internalization factors may be attributable to the different metabolic rates between tumor and normal cells. 


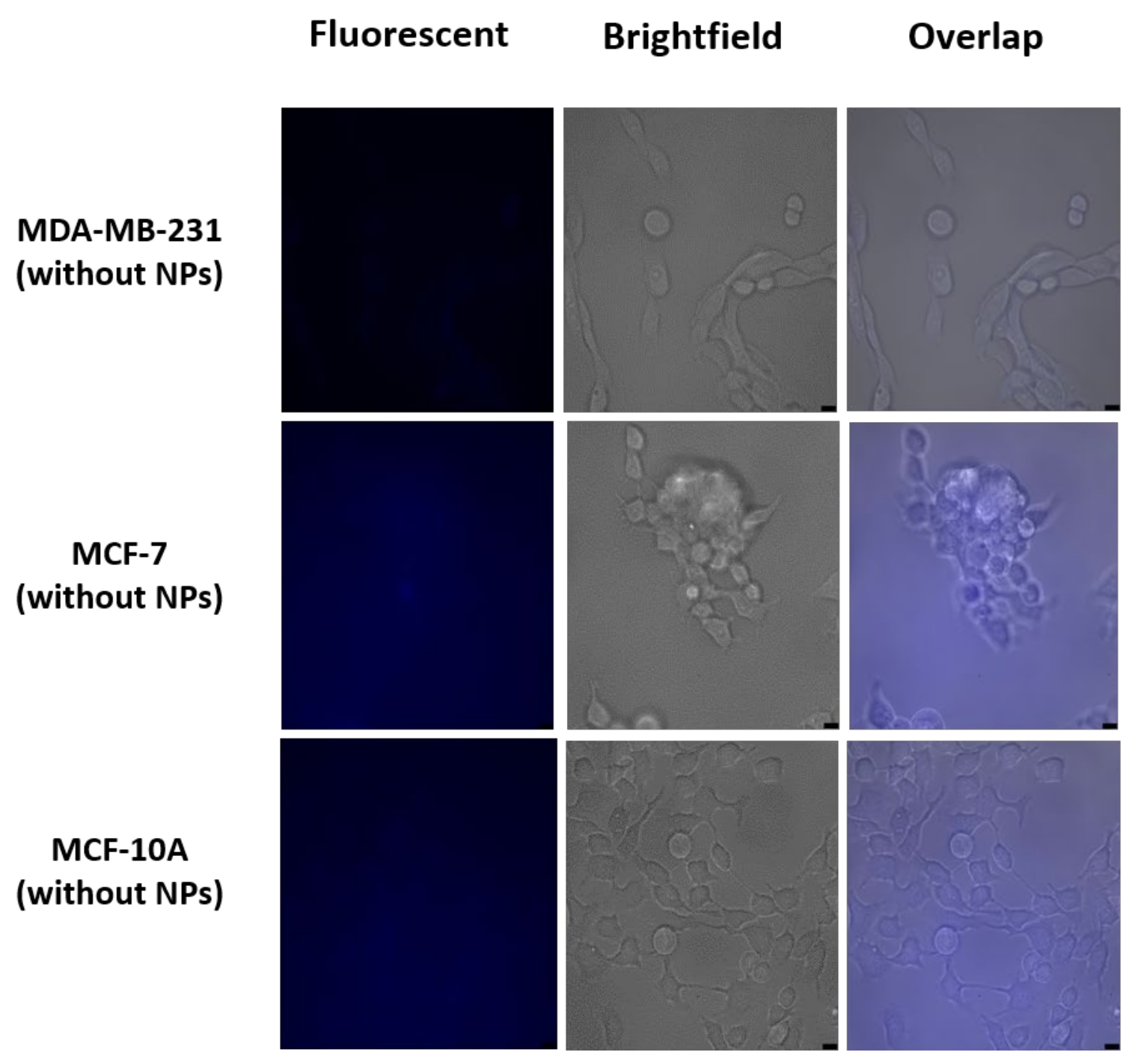

Supporting Figure S7.

Fluorescent, bright field, and overlay of fluorescence and bright field images of MDAMB-231, MCF-7, and MCF-10A cells without treatment by ITO NPs. 


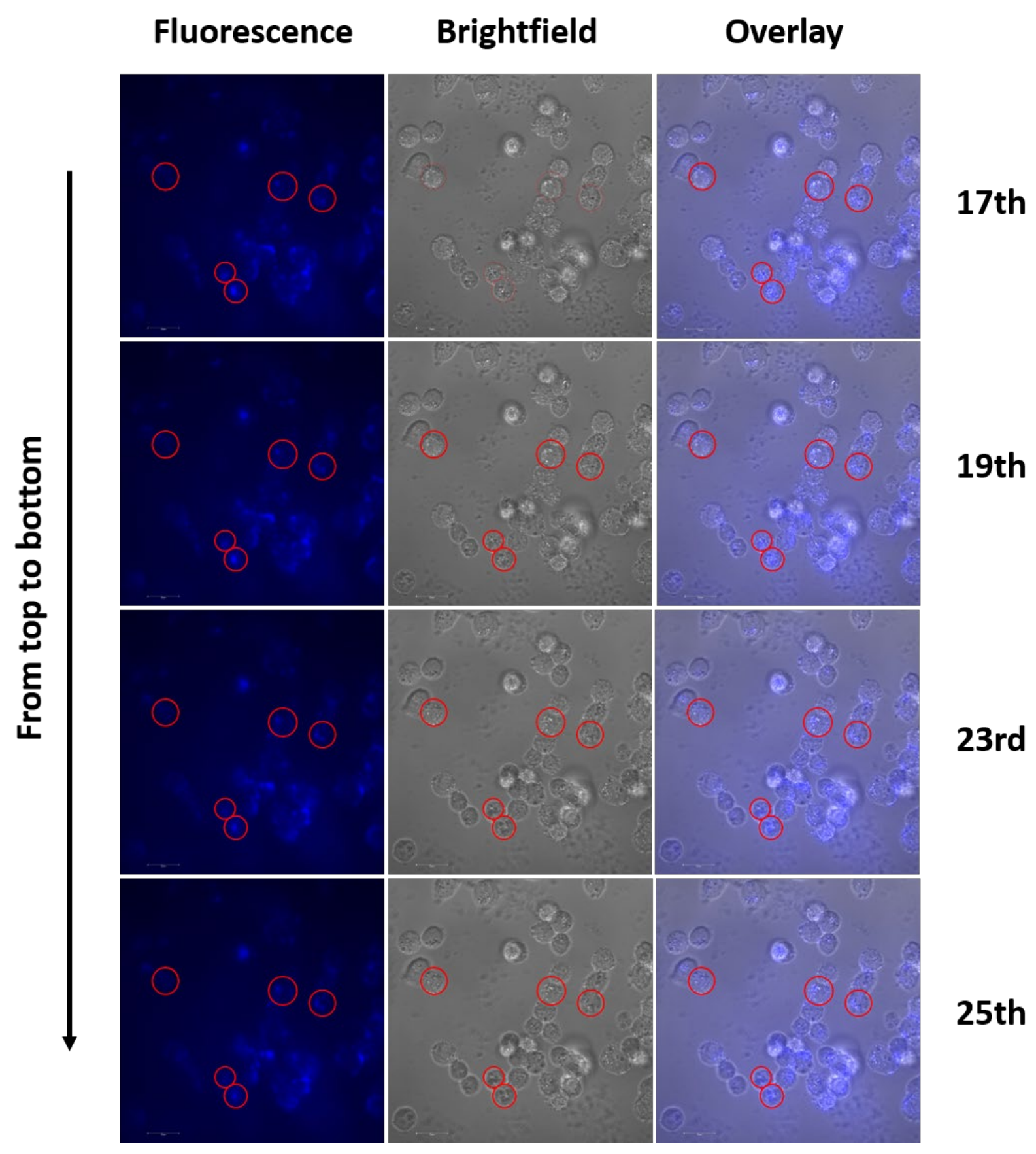

\section{Supporting Figure S8.}

Fluorescence images (left), bright field images (middle), and overlays of the fluorescence and bright field images (right), with the z-positions analysed through the $17^{\text {th }}, 19^{\text {th }}, 23^{\text {rd }}$, and $25^{\text {th }}$ sections of the MDA-MB-231 cells treated with ITO NPs for $24 \mathrm{~h}$. Red circles highlight the presence of ITO NPs in the cellular cytoplasm. 


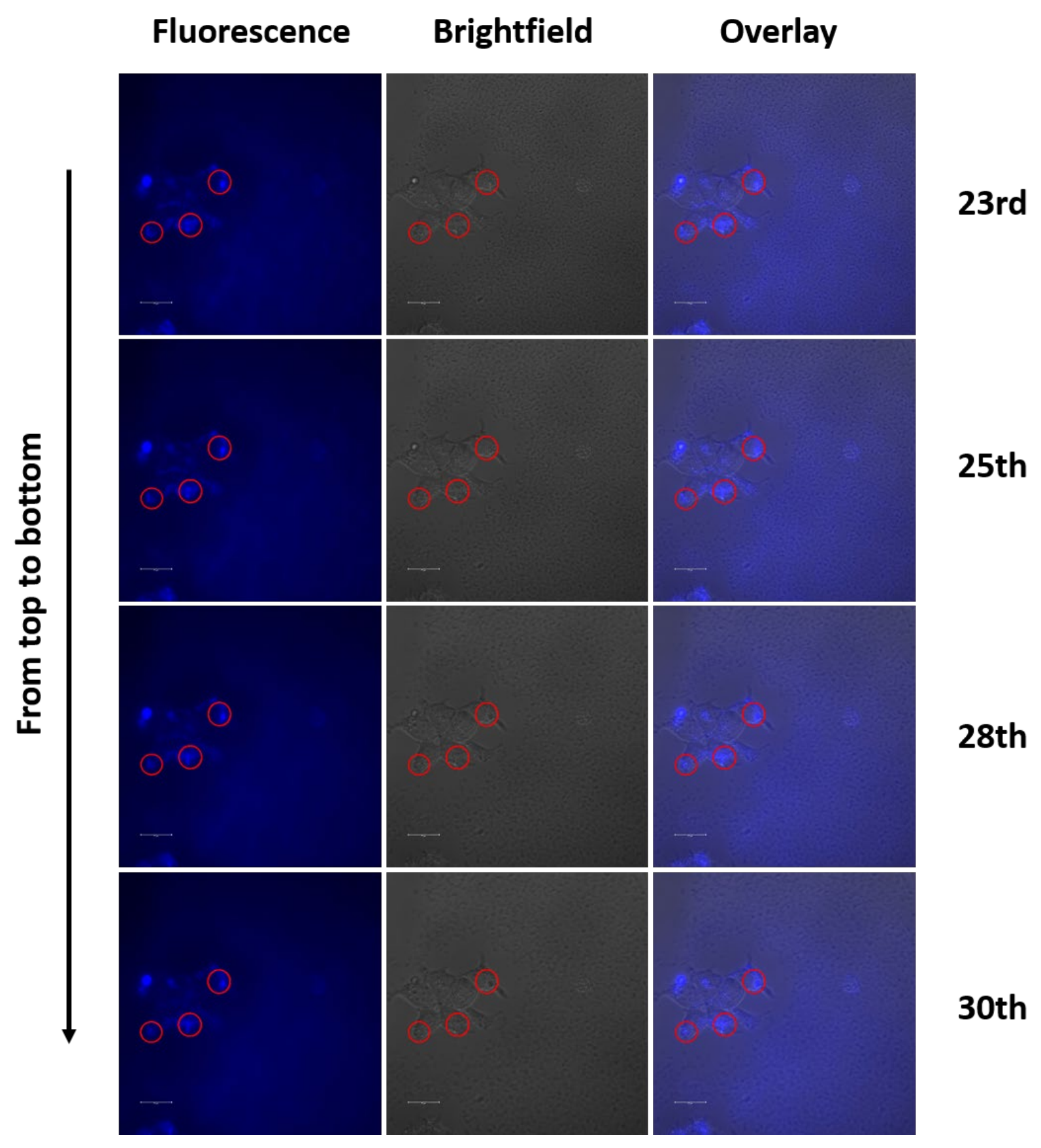

\section{Supporting Figure S9.}

Fluorescence images (left), bright field images (middle), and overlays of the fluorescence and bright field images (right), with the z-positions analysed through the $23^{\text {rd }}, 25^{\text {th }}, 28^{\text {th }}$, and $30^{\text {th }}$ sections of MCF-7 cells treated with ITO for $24 \mathrm{~h}$. Red circles highlight the presence of ITO NPs in the cellular cytoplasm. 


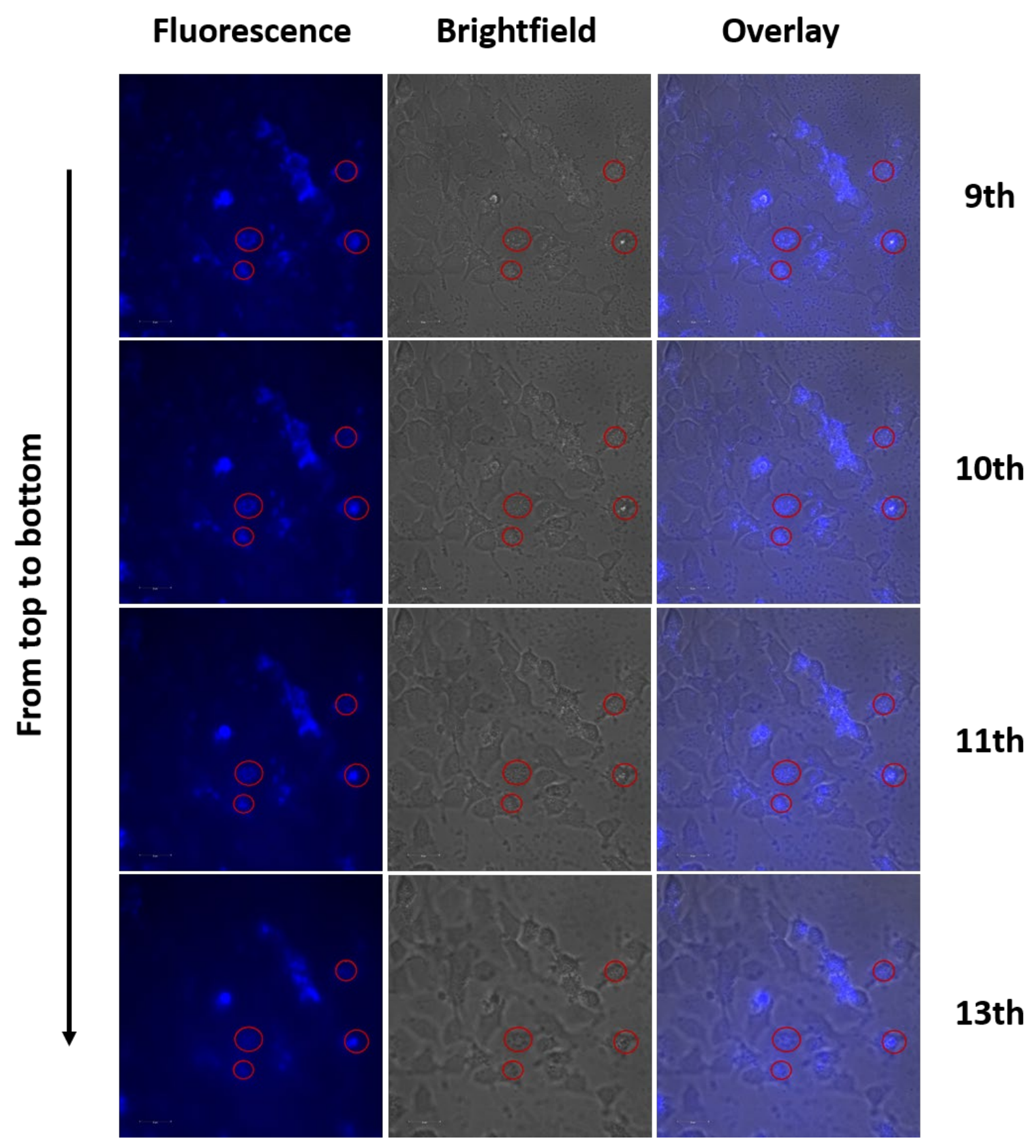

\section{Supporting Figure S10.}

Fluorescence images (left), bright field images (middle), and overlays of the fluorescence and bright field images (right), with the z-positions analysed through the $9^{\text {th }}, 10^{\text {th }}, 11^{\text {th }}$, and $13^{\text {th }}$ sections of MCF-10A cells treated with ITO for $24 \mathrm{~h}$. Red circles highlight the presence of ITO NPs in the cellular cytoplasm. 
A

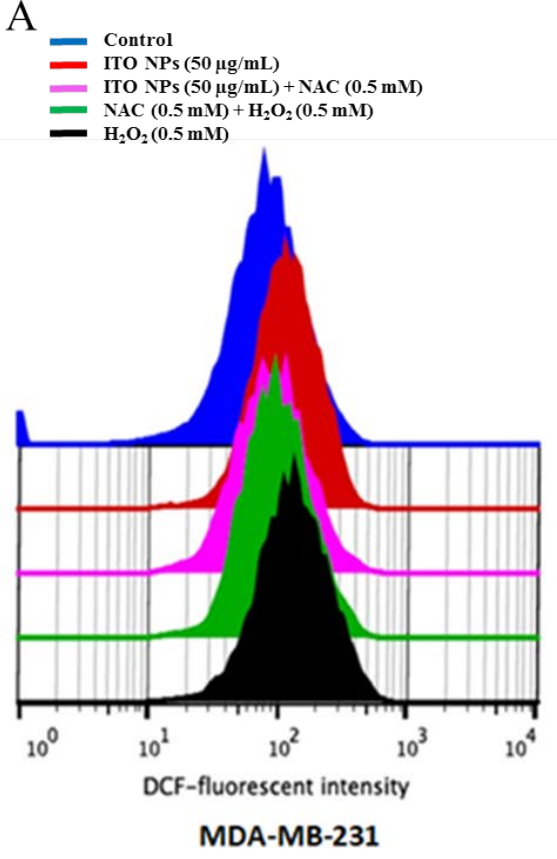

$\mathrm{B}$

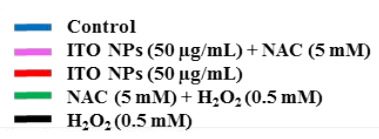

- ITO NPs $(50 \mu \mathrm{g} / \mathrm{mL})$

- $\mathrm{H}_{2} \mathrm{O}_{2}(0.5 \mathrm{mM})$

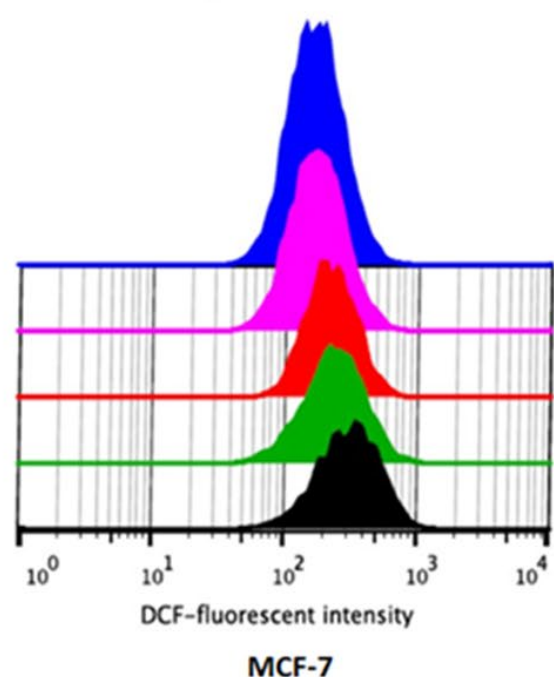

C

- Control

- ITO NPs $(50 \mu \mathrm{g} / \mathrm{mL})$ ITO NPs $(50 \mu \mathrm{g} / \mathrm{mL})+\mathrm{H}_{2} \mathrm{O}_{2}(0.5 \mathrm{mM})$ - NAC $(5 \mathrm{mM})+\mathrm{H}_{2} \mathrm{O}_{2}(0.5 \mathrm{mM})$ NAC $(5 \mathrm{mM})$ $-\mathrm{H}_{2} \mathrm{O}_{2}(0.5 \mathrm{mM})$

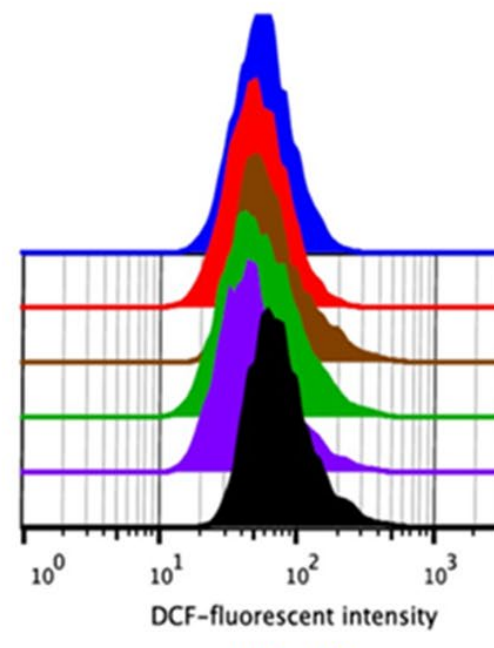

MCF-10A

\section{Supporting Figure S11.}

ITO NPs mediated production or scavenging of the intracellular ROS in MDA-MB-231, MCF-7, and MCF-10A cells. (A) and (B), Flow cytometric results of ITO NP induced generation of intracellular ROS in breast cancer MDA-MB-231 and MCF-7 cells, respectively.

(C) Flow cytometric results of ITO mediated prevention of intracellular ROS in normal MCF10A breast cells. 


\section{A}

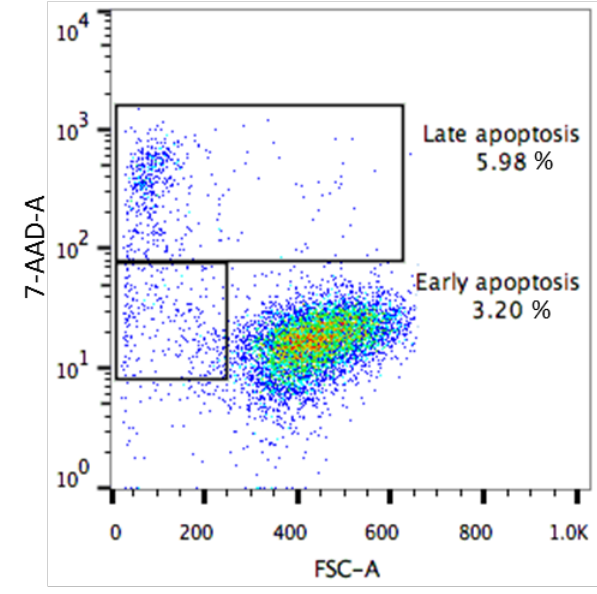

Control

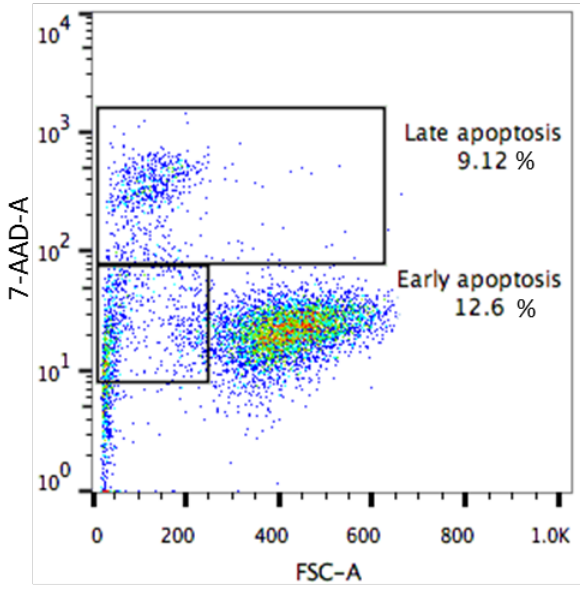

ITO NP $(50 \mu \mathrm{g} / \mathrm{mL})$

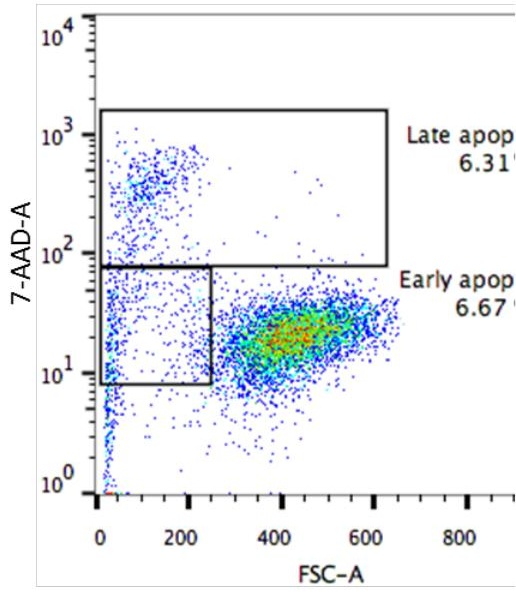

ITO NP $(50 \mu \mathrm{g} / \mathrm{mL})+\mathrm{NAC}(0.5 \mathrm{ml}$

B

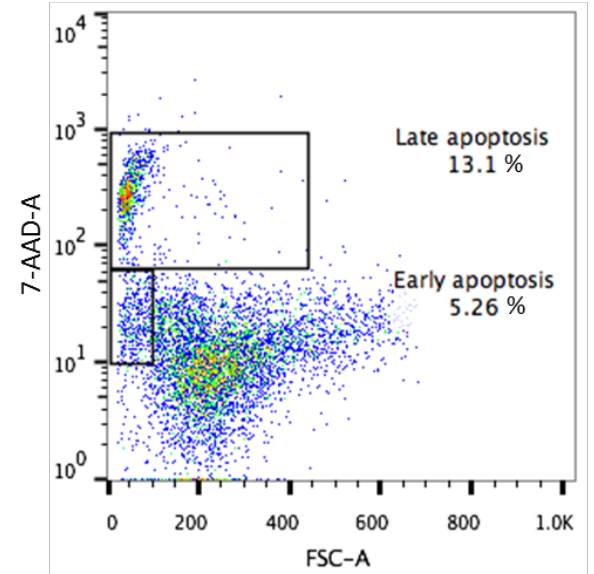

Control

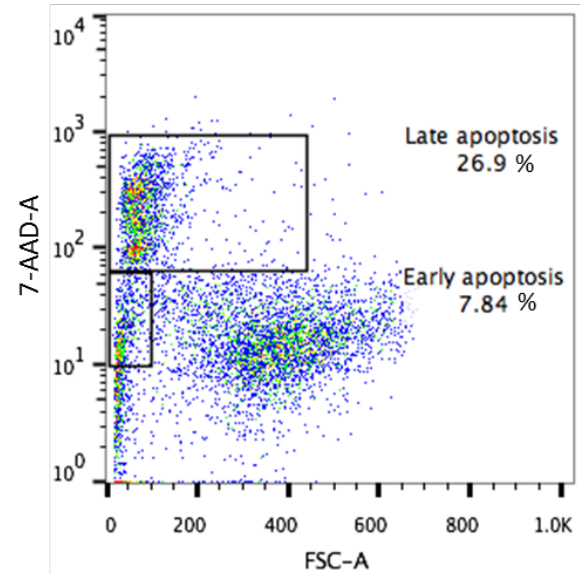

ITO NP $(50 \mu \mathrm{g} / \mathrm{mL})$

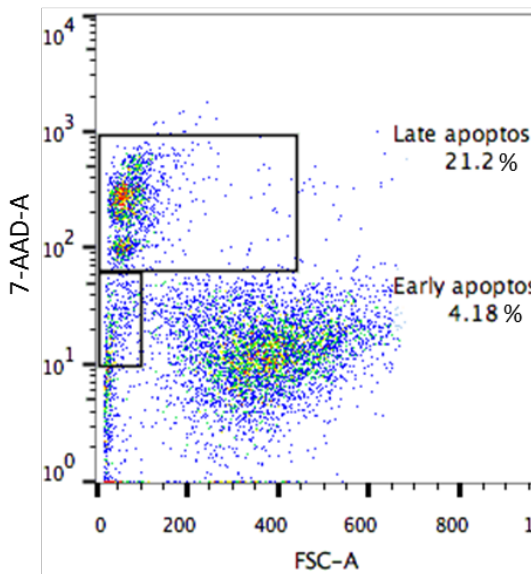

ITO NP $(50 \mu \mathrm{g} / \mathrm{mL})+$ NAC $(5 \mathrm{mM})$ 


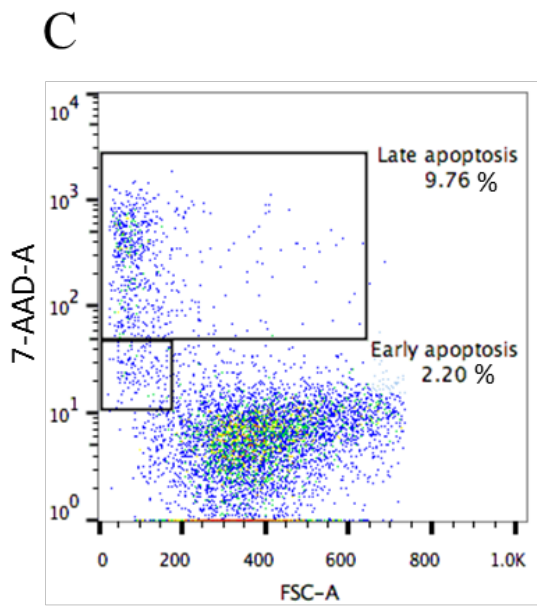

Control

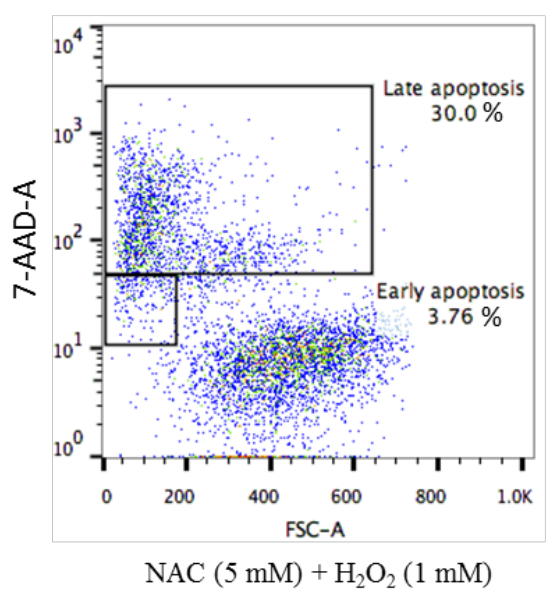

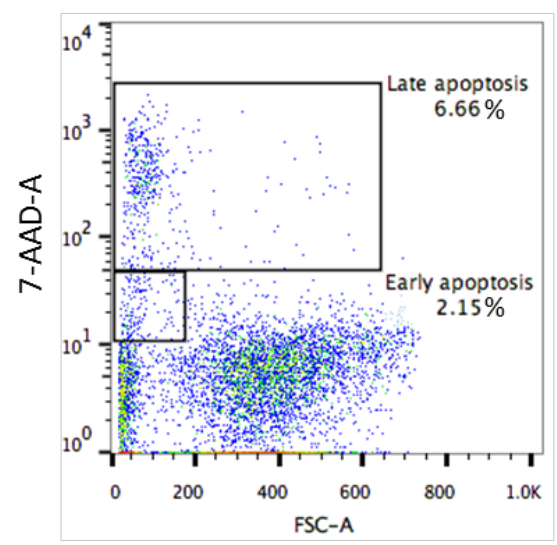

ITO NP $(50 \mu \mathrm{g} / \mathrm{mL})$

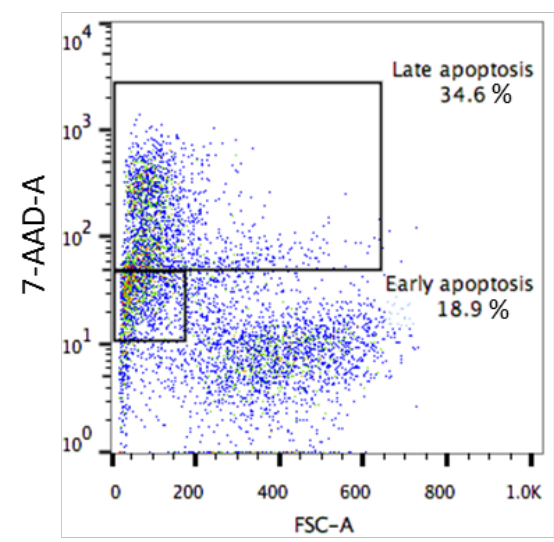

ITO NP $(50 \mu \mathrm{g} / \mathrm{mL}))+\mathrm{H}_{2} \mathrm{O}_{2}(1 \mathrm{mM})$
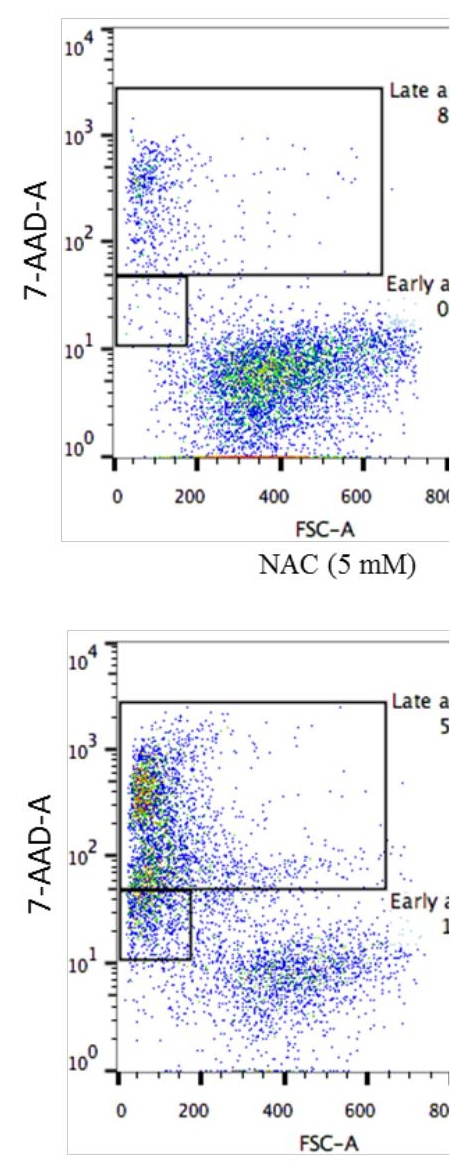

$\mathrm{H}_{2} \mathrm{O}_{2}(1 \mathrm{mM})$

\section{Supporting Figure S12.}

Scattergrams of 7-AAD stained cells with gating are shown. (A), Untreated MDA-MB-231 cells (left), MDA-MB-231 cells treated with ITO NP (middle), MDA-MB-231 cells treated with ITO NPs and $0.5 \mathrm{mM}$ of NAC (right); (B), Untreated MCF-7 cells (left), MCF-7 cells treated with ITO NPs (middle), MCF-7 cells treated with ITO NPs and $5 \mathrm{mM}$ of NAC (right); (C), Untreated MCF-10A cells (upper-left), MCF-10A cells treated with ITO NPs (uppermiddle), MCF-10A cells treated with $5 \mathrm{mM}$ of NAC (upper-right), MCF-10A cells treated with $5 \mathrm{mM}$ of NAC and $1 \mathrm{mM}$ of $\mathrm{H}_{2} \mathrm{O}_{2}$ (bottom-left), MCF-10A cells treated with ITO NPs and $1 \mathrm{mM}$ of $\mathrm{H}_{2} \mathrm{O}_{2}$ (bottom-middle), and MCF-10A cells treated with $1 \mathrm{mM}$ of $\mathrm{H}_{2} \mathrm{O}_{2}$ (bottom-right).

Note for Supporting Figure S12: The concentration of the ITO NPs used for treatments was $50 \mu \mathrm{g} / \mathrm{mL}$. The legend of "Late apoptosis" in all panels represents both late apoptotic and dead cell populations. 
9L

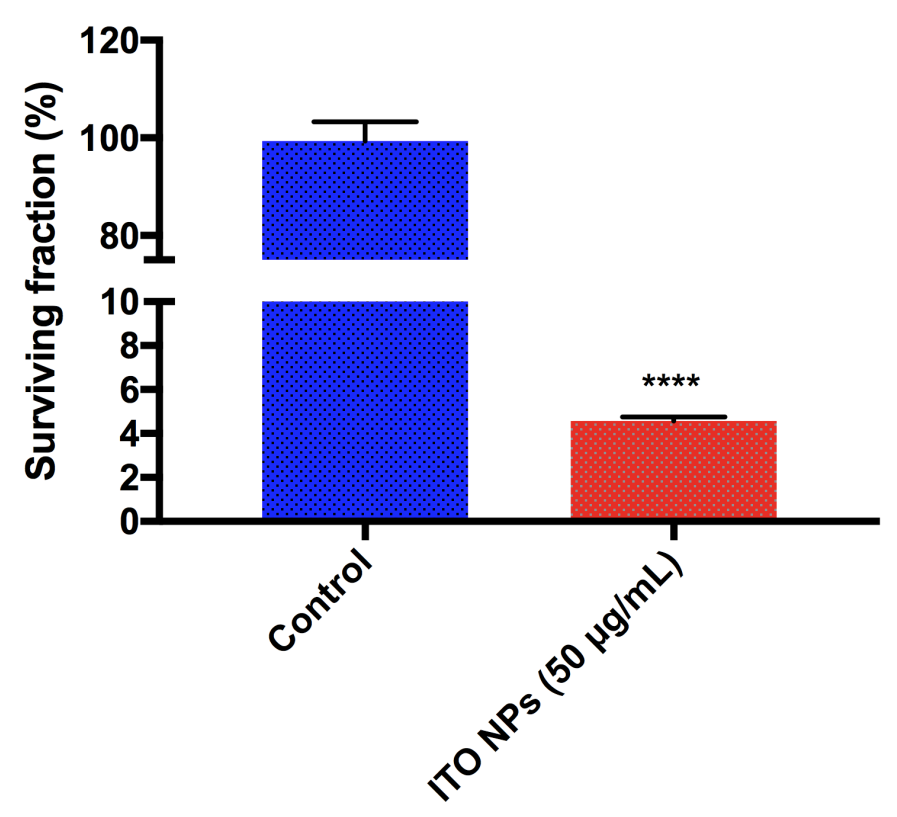

MDCK

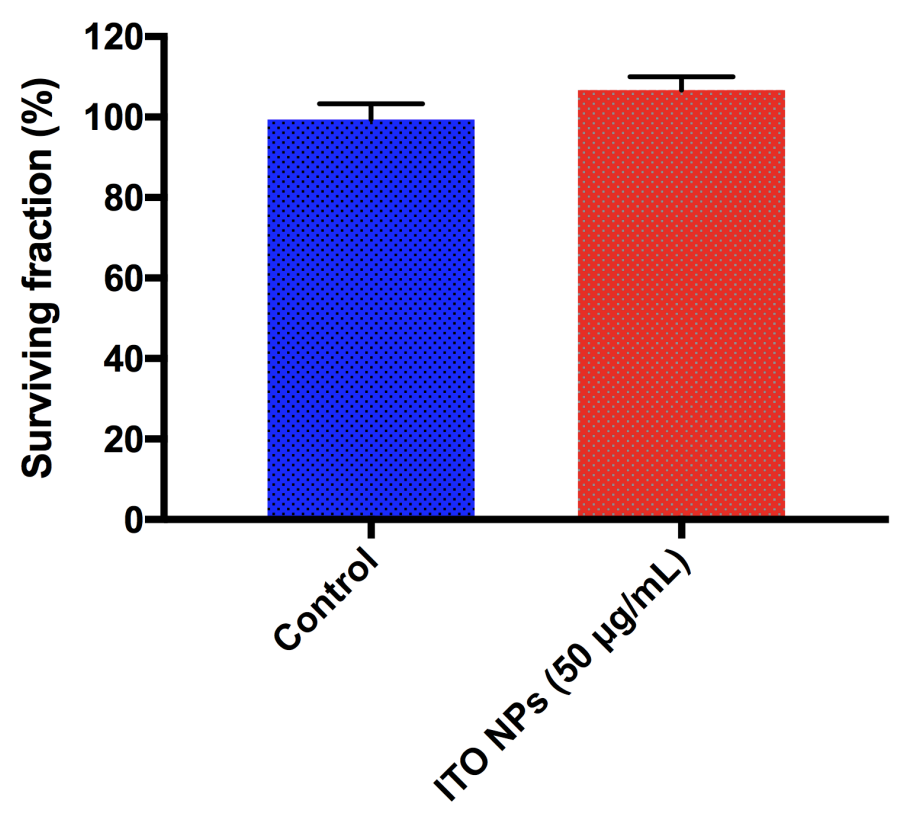

\section{Supporting Figure S13.}

Quantitative clonogenic results for 9L (left) and MDCK cells (right) treated with and without ITO NPs. The concentration of ITO NPs for the treatment was $50 \mu \mathrm{g} / \mathrm{mL}$. "Control" represents the samples without treatment. $* * * *$ indicates $\mathrm{p}<0.0001$ for the comparison with the untreated control. 